\title{
The Dynamic Change of Bosten Lake Area in Response to Climate in the Past 30 Years
}

\author{
Xiaoai Dai ${ }^{1, * \mathbb{D}}$, Xingping Yang ${ }^{1, *}$, Meilian Wang ${ }^{2} \mathbb{D}$, Yu Gao $^{1}$, Senhao Liu ${ }^{3}$ and Junmin Zhang ${ }^{1}$ \\ 1 School of Earth Science Chengdu University of Technology, Chengdu 610059, China; \\ gao7819@foxmail.com (Y.G.); zhangjunmin130@163.com (J.Z.) \\ 2 Hong Kong Polytechnic University, Hongkong 999077, China; meilianp.wang@connect.polyu.hk \\ 3 Aerospace Information Research Institude Chinese Academy of Sciences, Beijing 100049, China; \\ liusenhao19@mails.ucas.ac.cn \\ * Correspondence: daixiaoai@163.com (X.D.); yangxingping996@163.com (X.Y.)
}

Received: 26 November 2019; Accepted: 16 December 2019; Published: 18 December 2019

\begin{abstract}
The widely distributed lakes, as one of the major components of the inland water system, are the primary available freshwater resources on the earth and are sensitive to accelerated climate change and extensive human activities. Lakes play an important role in the terrestrial water cycle and biogeochemical cycle and substantially influence the health of humans living in the surrounding areas. Given the importance of lakes in the ecosystem, long-term monitoring of dynamic changes has important theoretical and practical significance. Here, we extracted water body information and monitored the long-term dynamics of Bosten Lake, which is the largest inland lake in China. We quantified the meteorological factors of the study area from the observation data of meteorological stations between 1988 and 2018. The characteristics of climate change and its correlation with the change of area in the Bosten Lake Basin in the past 30 years were analyzed. The major contributions of this study are as follows: (1) The initial water body was segmented based on the water index model Normalized Difference Water Index (NDWI) and Modified Normalized Difference Water Index (MNDWI) with a pre-assigned threshold value. The results were evaluated with the area extracted through artificial visual interpretation. Then we conducted mathematical morphology operators, opening and closing operations, and median filter to eliminate noise to ensure the accuracy of water body information extraction from the Bosten Lake. A long-term water surface area database of the Bosten Lake was established from high-resolution remote sensing images during 1988-2018. (2) Due to the seasonal difference of snow, ice content, and other objects on images, the areadynamics of Bosten Lake in the recent 30 years were analyzed separately in dry season and rainy season. The water surface area of Bosten Lake showed large inter-annual variations between 1988-2018. (3) Based on the assumption that climatic change has more direct effects on lake than human activities, six meteorological factors were selected to analyze the impacts of climate change on the annual mean lake surface area. The result indicated that in the past 30 years, climate conditions in the Bosten Lake Basin fluctuated greatly. We conducted correlations analysis between the areal dynamics of the Bosten Lake and the meteorological factors. Here, the annual average evaporation had the highest correlation with the areal dynamics of Bosten Lake followed by air temperature, precipitation, sunshine hours, and relative humidity, while the annual average wind speed had the weakest correlation.
\end{abstract}

Keywords: Bosten Lake; water body information extraction; area change; climate response

\section{Introduction}

Under the influence of dramatic global climate changes, a series of environmental problems, such as global temperature rising, accelerated melting of glaciers, and declining lakes, have severely affected 
the sustainability of the ecological environment and threatened the recycling of the ecological resources in various countries, increasing the cost of ecological environment governance [1,2]. The Bosten Lake, which is located in Yanqi Basin, is the largest inland freshwater lake in China. As the global climate condition deteriorates gradually, the Bosten Lake is shrinking and the water level fluctuating largely. Also, the biodiversity of the surrounding environments has been seriously decreased.

The reduction of the number of species substantially altered the food chain structure of the terrestrial and aquatic ecosystems, which in turn induced a series of ecological problems. Thus, the ecological restoration capacity is greatly weakened and the daily life of people in Bazhou County is severely affected [3].

\subsection{Research Progress on Remote Sensing Water Body Extraction Methods}

In the early years of remote sensing technology, researchers usually extracted water surface area through manual visual interpretation methods, although it is time consuming, labor intensive, and it is not capable of monitoring the lake area change in the long term due to too much data $[4,5]$. With the development of science and technology in recent decades, more and more water extraction models were being proposed and widely applied in many countries.

Bartolucci L A. et al. [6] found that clear water shows strong absorption characteristics in the near-infrared band, and Multi-Spectral Scanner (MSS) near-infrared band is the best choice for water information extraction. This characteristic was utilized by Shih [7] to extract water information subsequently and the results indicated that the water area obtained by the single-band density slice method on the MSS near-infrared band was similar to the area obtained by the unsupervised classification method on the fifth band. The density slice method and Earth Resources Laboratory Application Software (ELAS) have similar accuracy in water surface area classification ( $<3 \%$ difference) [6,7]. With the emergence of Thematic Mapper (TM) data, lots of researchers explored a new study for water extraction and have made large progress. For example, Horwitz et al. [8] extracted the water body through the ratio of single components of mixed pixels based on mathematical theory and thus introduced the "proportional measurement" for the first time. Mcfeeters [9] built a normalized difference water index (NDWI) on the basis of a normalized difference vegetation index (NDVI) according to the difference between digital values of the visible bands and near-infrared band in the image, which was able to highlight the water information for extraction; but this index is not effective when removing buildings and soil. To avoid noise, the modified normalized difference water index (MNDWI), which replaced the near-infrared band in NDWI with mid-infrared band, was created by $\mathrm{Xu}[10]$ in the light of the obvious characteristic of water in the mid-infrared band. After that, various widely used indices based on NDWI were generated. Mo et al. [11] built a combined index of Normalized Difference Vegetation Index (NDVI) and Mid-Infrared band (MIR) for water body identification (CIWI). Yan et al. [12] proposed an enhanced vegetation index (EVI). Ding et al. [13] created a new water index (NWI). In addition, Lu et al. [14] demonstrated that the multi-band threshold method can reduce the error of manual visual interpretation, but this method is only applicable to water bodies with an area of more than $4000 \mathrm{~m}^{2}$ and there are still problems of shadow misjudgment. Zhou et al. [15] established a water body description model based on the characteristics of $\mathrm{TM}_{2}+\mathrm{TM}_{3}$ $>\mathrm{TM}_{4}+\mathrm{TM}_{5}$. This model not only achieves the extraction of water body with large area, but also can eliminate the influence of shadow to some extent [15]. In the past 20 years, the development of new hybrid water index based on the combination of water index and single-band threshold algorithm remains stable.

\subsection{Research Progress on Dynamic Monitoring of Lake Area and Its Influencing Factors}

In the early 1980s, based on the rapid development of $3 S$ technology, many scholars started to monitor the dynamic changes of lakes with $3 S$ technology and began to study the correlation between lake dynamic and climate change under the influence of global climate. As a result, the inherent 
problem of lake dynamic change was broken internationally, opening new theories and methods for the research of lake dynamic change in a wide range over a long time period effectively [16].

Harris et al. [17] explored the response relationship between lake dynamic and lake water level with mathematical statistics theory based on the monitoring of dynamic changes in lakes using remote sensing technology. Then, they extracted the fundamental variables of lakes such as water surface area and depth from long-term Advanced Very High Resolution Radiometer (AVHRR) and Thematic Mapper (TM) imagery, and explored the degree of interaction between the area dynamic changes and water depth of Lough Lake in Northern Ireland utilizing correlation model and Geographic Information System (GIS) technology [17].

Charon et al. [18] established a database of seasonal changes and inter-annual changes of the Caspian Sea over a long time based on remote sensing technology.

Guirguis et al. [19] detected the dynamic changes of lake area employing a principal component analysis based on long-term images of Brullus Lake in false color from 1983 to 1991, and they found that the area changes were related to human behaviors, and artificial cofferdams had the most significant impact.

The dynamic area changes of Peace-Athabasca Delta in Canada were monitored by Pietronir et al. [20] with multi-temporal, long-sequence MSS, TM imageries. They built a database of lake area in a long time and analyzed the driving factors of dynamic area changes and their characteristics [20]. Laabs et al. [21] extracted the lake depth and water level of Bear Lake from the sediments of Bear Lake Basin and detected their changes with inversion techniques with the help of remote sensing technology and geology theory. In addition, the relationships between water level dynamics and regional climate and hydrological changes were explored by them using meteorological and hydrological data [21]. Li et al. [22] monitored the characteristics of area change of northern Tibetan Plateau Lake and surrounding climate changes with remote sensing techniques.

Most Chinese scholars employ methods such as artificial visual interpretation, water indices, threshold segmentation, single-band threshold as well as mathematical morphology to extract the information of water body from long-term Landsat and MODIS imagery. The statistical algorithms are utilized to explore and analyze the correlation between lake area change and the kinds of its driving factors like climate dynamics and human behaviors and so on. Some suggestions have been provided for the management of lakes and ecology [23-28]. Recent studies about the monitoring of lake area dynamic changes of Chinese researchers has been summarized in Table 1.

Table 1. Some studies about dynamic changes of lakes and corresponding climate changes in China.

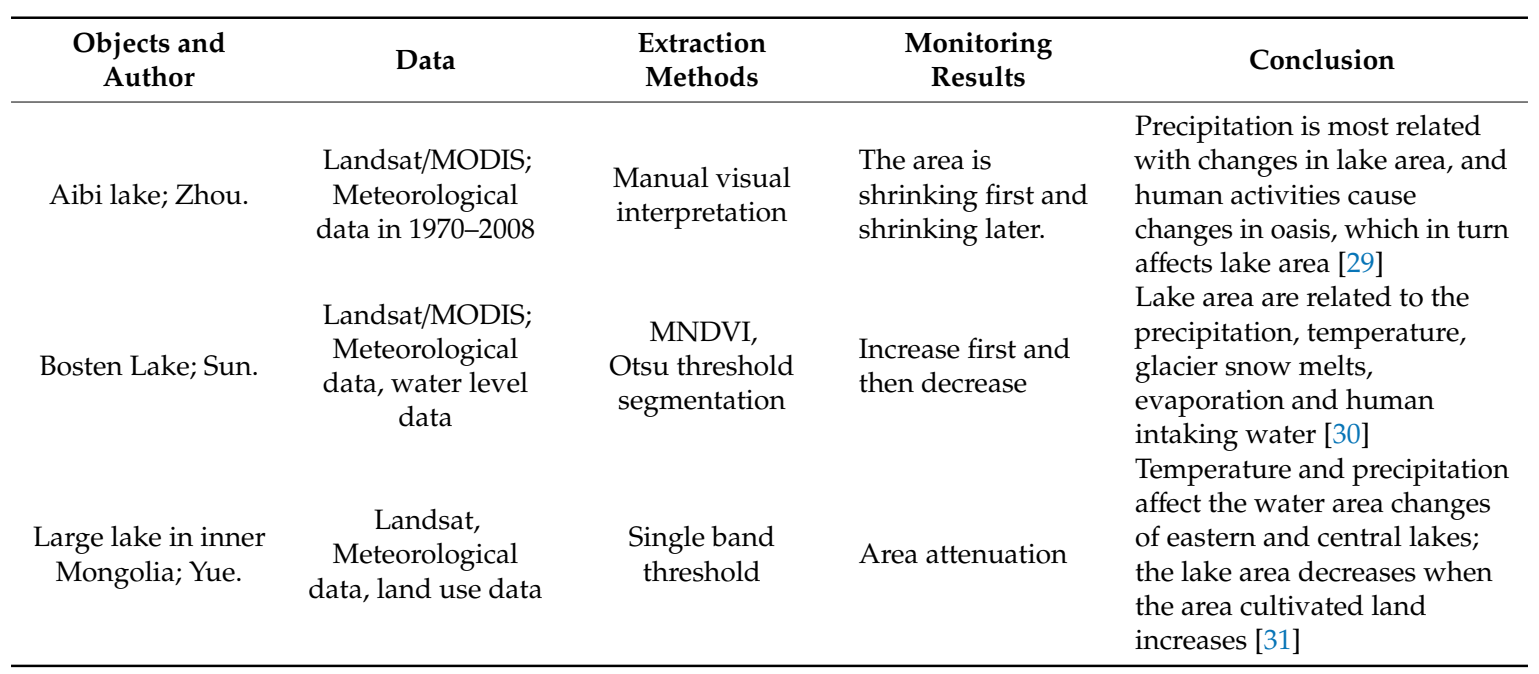


Table 1. Cont.

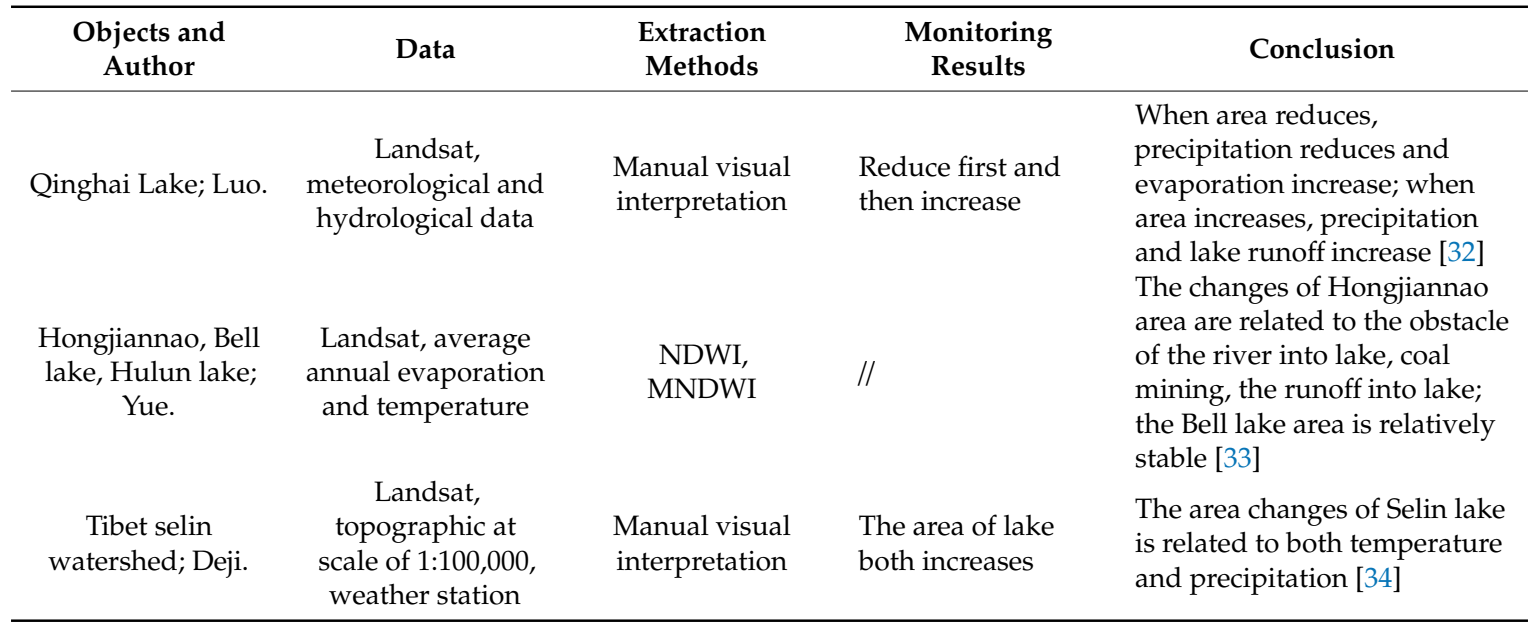

The purpose of this study was to investigate the correlation between the dramatic changes in the ecological environment especially the lake dynamics and climate change driving factors in the context of global climate changes, to provide a basic theory for preventing and controlling the declining and governance problems of lakes, thus to provide technical and theoretical support for the management of water and meteorological research.

\section{Materials and Methods}

\subsection{Research Area}

Bosten Lake is located in BazhouaCounty, where the Bayinguoleng Mongolian autonomous prefecture is, southeast of Xinjiang Uygur autonomous region. It has a long span of $55 \mathrm{~km}$ from east to west and a width of $25 \mathrm{~km}$ from north to south. The total water area is approximately $800 \mathrm{~km}^{2}$. As the largest inland freshwater lake in China, its water injection and outflow are huge. In addition, Bosten Lake is one of the most famous mountain lakes in China as it is located in the basin of the mountain and the surrounding terrain is high in the north and low in the south. From the foot of the mountain to Bosten Lake there are piedmont alluvial-alluvial slope plains, the Kaidu River delta, and the Bosten Lake Basin $[27,35]$. The main geographical distribution can be seen in Figure 1. 


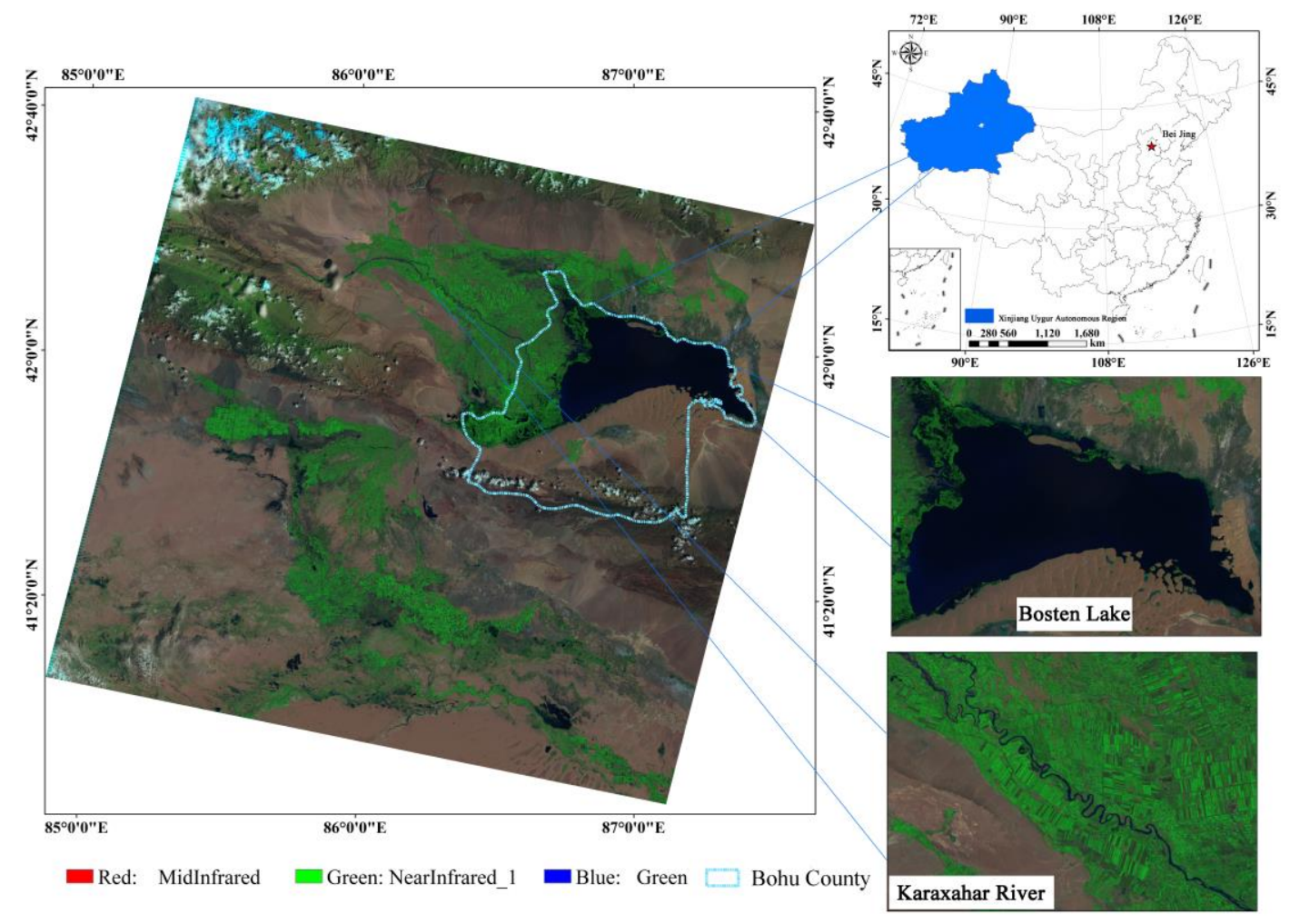

Figure 1. Location of research area.

\subsection{Data Sources and Data Preprocessing}

\subsubsection{Remote Sensing Data Sources and Preprocessing}

The remote sensing data used in this study included the Landsat4-5 images in 1988, 1993, 2003, and 2008, Landsat 7 ETM+ in 2013, and Landsat8 OLI images in 2013 and 2018, respectively. The detailed information is shown in Table 2.

Table 2. Remote sensing data sources.

\begin{tabular}{ccccccc}
\hline \multirow{2}{*}{ Year } & \multicolumn{3}{c}{ Drought Season } & & Wet Season \\
\cline { 2 - 6 } & Specific Time & Data Sources & Path/Raw & Specific Time & Data Sources & Path/Raw \\
\hline 1988 & 5 January 1988 & Landsat5 TM & P142/R031 & 28 May 1988 & Landsat5 TM & P142/R031 \\
1993 & 2 January 1993 & Landsat5 TM & P142/R031 & 29 July 1993 & Landsat5 TM & P142/R031 \\
1998 & 6 April 1998 & Landsat5 TM & P142/R031 & 2 July 1998 & Landsat5 TM & P142/R031 \\
2003 & 19 March 2003 & Landsat5 TM & P143/R031 & 16 July 2003 & Landsat5 TM & P142/R031 \\
2008 & 13 February 2008 & Landsat5 TM & P142/R031 & 13 July 2008 & Landsat5 TM & P143/R031 \\
2013 & 18 February 2013 & Landsat7 ETM+ & P142/R031 & 4 July 2013 & Landsat8 OLI & P143/R031 \\
2018 & 23 January 2018 & Landsat8 OLI & P142/R031 & 9 July 2018 & Landsat8 OLI & P143/R031 \\
\hline
\end{tabular}

The image preprocessing refers to the technology of data processing using professional image processing tools to enhance the information of interest for the necessary procedure before analysis of study imagery on the specific theme [36]. All 14 images were downloaded from United States Geological Survey (USGS) and they were preprocessed roughly. To ensure the accuracy of remote sensing data for lake area dynamic monitoring and climate change response, the data preprocessing in this study includes: (1) Removal of Landsat 7 E1M+ image strips, (2) radiation calibration, (3) atmospheric correction, (4) geometric correction, (5) unified mathematical basis, and (6) image cropping [36,37]. The Figure 2 shows the image preprocessing result of the Bosten Lake during drought season and the Figure 3 shows the image preprocessing result of the Boeten Lake during wet season. 

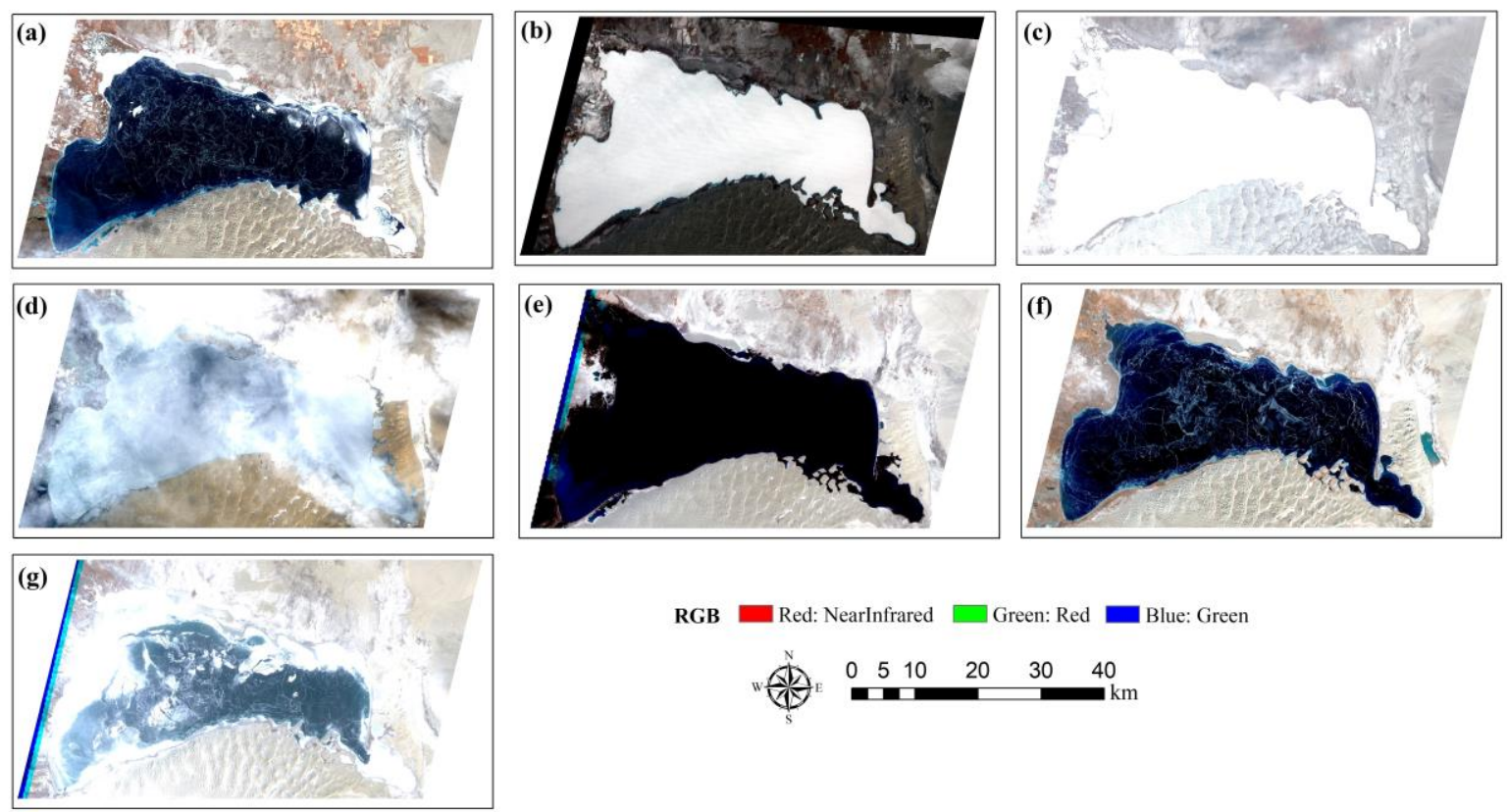

Figure 2. The results of image preprocessing of the Bosten Lake during drought season. (a) 2 January 2018, (b) 18 February 201, (c) 13 February 2008, (d) 19 March 2003, (e) 6 April 1998, (f) 2 January 1993. (g) 5 January 1988.
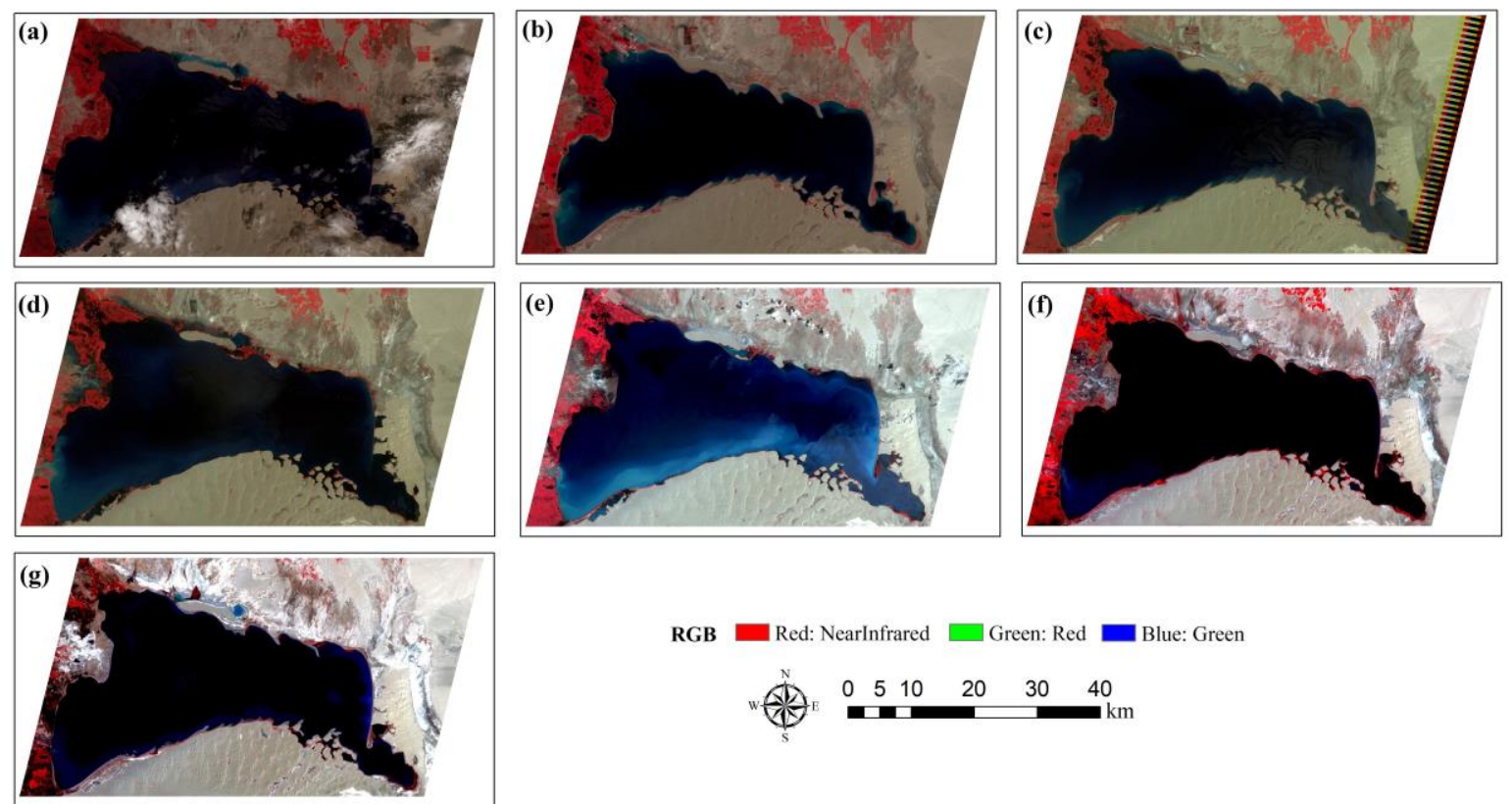

RGB Red: NearInfrared $\square$ Green: Red $\square$ Blue: Green

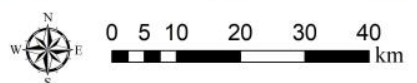

Figure 3. The results of image preprocessing of the Bosten Lake during wet season. (a) 9 July 2018, (b) 4 July 2013, (c) 13 July 2008, (d) 16 July 2003, (e) 2 July 1998, (f) 29 July 1993, (g) 28 May 1988.

\subsubsection{Meteorological Data Sources and Preprocessing}

The meteorological observation data used in this paper were all acquired from Xinjiang Meteorological Information Center, including the meteorological observation data of 72 stations in Xinjiang from 1961 to 2018. We selected the observation data from five stations around Bosten Lake in 1988-2018, i.e., Hejing, Yanqi, Heshuo, Yuli, and Korla stations [29].

On the basis of six factors (annual average precipitation, annual average temperature, annual average sunshine hours, annual average evaporation, annual average relative humidity, and annual average wind speed) [38-41] this paper selected meteorological data at intervals of 5 years from 
1988-2018, and then built meteorological databases of drought season and wet season, respectively. Finally, the meteorological factors of Bosten Lake Basin were obtained through factor interpolation calculation of five meteorological stations by ordinary kriging interpolation algorithm [39,41-43]. The statistics are shown in Table 3.

Table 3. Interpolation results of meteorological factors in the Bosten Lake Basin.

\begin{tabular}{|c|c|c|c|c|c|c|c|}
\hline \multicolumn{2}{|c|}{ Time } & $\begin{array}{l}\text { Precipitation } \\
(\mathrm{mm})\end{array}$ & $\begin{array}{c}\text { Average } \\
\text { Temperature } \\
\left({ }^{\circ} \mathrm{C}\right)\end{array}$ & $\begin{array}{l}\text { Evaporation } \\
(\mathrm{mm})\end{array}$ & $\begin{array}{c}\text { Relative } \\
\text { Humidity (\%) }\end{array}$ & $\begin{array}{l}\text { Sunshine } \\
\text { Hours (h) }\end{array}$ & $\begin{array}{c}\text { Average } \\
\text { Wind Speed } \\
(\mathrm{m} / \mathrm{s})\end{array}$ \\
\hline \multirow{7}{*}{$\begin{array}{l}\text { Drought } \\
\text { season }\end{array}$} & $1988 / 1 / 5$ & 82.5235 & 9.6663 & 2202.6647 & 53.8322 & 3031.1808 & 1.6177 \\
\hline & $1993 / 1 / 2$ & 49.9235 & 10.0655 & 1803.5924 & 55.4151 & 2835.3174 & 1.8041 \\
\hline & $1998 / 4 / 6$ & 111.8216 & 10.5409 & 1513.2970 & 57.6235 & 2816.8707 & 1.4988 \\
\hline & 2003/3/19 & 121.6576 & 8.9732 & 1594.5166 & 55.7143 & 2904.5186 & 1.8999 \\
\hline & $2008 / 2 / 13$ & 111.0922 & 10.3671 & 1740.0632 & 53.7567 & 3052.5448 & 1.8418 \\
\hline & $2013 / 2 / 18$ & 60.2906 & 9.9337 & 2246.2888 & 53.6107 & 2854.0078 & 1.7534 \\
\hline & $2018 / 1 / 23$ & 79.0712 & 10.2401 & 961.9000 & 56.4963 & 2798.2397 & 1.8684 \\
\hline \multirow{7}{*}{$\begin{array}{c}\text { Wet } \\
\text { season }\end{array}$} & $1988 / 5 / 28$ & 82.8695 & 9.6454 & 2202.1579 & 53.8424 & 3031.0417 & 1.6182 \\
\hline & $1993 / 7 / 29$ & 82.8422 & 10.0755 & 1803.3700 & 55.4141 & 2835.6189 & 1.8049 \\
\hline & $1998 / 7 / 2$ & 111.6616 & 10.5506 & 1513.5442 & 57.6384 & 2816.7138 & 1.4967 \\
\hline & 2003/7/16 & 121.7418 & 8.9697 & 1594.5169 & 55.7029 & 2904.2688 & 1.8868 \\
\hline & $2008 / 7 / 13$ & 111.6030 & 10.3479 & 1740.7552 & 53.7793 & 3051.8216 & 1.8389 \\
\hline & $2013 / 7 / 4$ & 60.0803 & 9.9437 & 2247.4422 & 53.5507 & 2855.4386 & 1.7545 \\
\hline & $2018 / 7 / 9$ & 80.0805 & 10.2121 & 961.9000 & 56.5121 & 2796.0551 & 1.8648 \\
\hline
\end{tabular}

\subsubsection{Other Auxiliary Data}

Apart from Landsat imagery and meteorological data in the study area, other auxiliary data were collected, such as national economic and social development data of Bazhou County in 2014-2018 [44-48] and boundaries of cities, districts, and counties in Xinjiang, as well as vector data of main rivers all over the country.

\subsection{Water Extraction Methods}

According to the geographical location, topographical differences, meteorological characteristics, and hydrological characteristics of lakes, the conventional water body extraction methods were utilized, including a single-band threshold [6,7], multi-band spectral relationship method [8], water index method [9], and post-classification extraction method [10]. The varied reflection rates of water in different bands and the differences of reflection rates between water and other objects can be employed to establish a water index. Therefore, we utilized an improved single- band threshold and improved multi-band spectral relationship method as a water index, which included the combination of NDWI and a series of improved indices [4,14].

Considering the accuracy of water information extraction due to the characteristics of large injection and outflow of the Bosten Lake, we chose an image segmentation algorithm based on the threshold values derived from NDWI and MNDWI [15] to extract water information of 14 images and evaluated the accuracy through water area obtained by manual visual interpretation [26]. The water index can effectively reduce the influence of other features and its format can be changed according to the difference between images in various time with the help of the threshold algorithm to ensure the accuracy of basic data. Compared with other methods, water information can be obtained quickly and effectively by this method.

$$
\mathrm{NDWI}=\frac{\mathrm{NIR}-\mathrm{MIR}}{\mathrm{NIR}+\mathrm{MIR}}
$$

where NIR is near-infrared band, MIR is mid-infrared band.

$$
\text { MNDWI }=\frac{\text { Green }- \text { MIR }}{\text { Green }+ \text { MIR }}
$$

where Green is green band. 


\subsubsection{Selection of Global Threshold T}

The exponential knowledge model can be used to separate background and target objects through an extraction algorithm through enhancing the reflection rates of targets and reducing the reflection of other objects at the same time after analysis of combination of bands that best reflect the characteristics of the kinds of objects in the remote sensing data [16]. On the basis of the characteristics of 14 remote sensing images, this paper took two images at drought season and wet season as examples, and selected the corresponding index as the threshold reference to achieve the extraction of target information.

Because the images in the wet season were relatively clear and there was no cloud in the study area, we built the $T \alpha$ index model as a threshold reference according to the characteristics of bands $[15,38,49,50]$.

$$
T_{\alpha}=\left(X_{4}+X_{5}+X_{7}\right)-X_{3}-X_{2}
$$

among which, $T \alpha$ is water index in the wet season, $X_{4}, X_{5}, X_{7}, X_{3}$, and $X_{2}$ are red band, near-infrared band, short-wave infrared band, green band, and blue band, respectively.

The water index of the wet season was established based on MNDWI defined by $\mathrm{Xu}$. The reasons include: (1) Clearly distinguishing the interference information such as ice and snow and (2) all satellite data now contained near-infrared band and green band around the world so that MNDWI can be used to almost remote sensing data. Therefore, it was more suitable and accurate to employ this model for monitoring of lake changes from long-term datasets [50,51].

$$
\begin{gathered}
\text { MNDWI }=\frac{X_{3}-X_{7}}{X_{3}+X_{7}} \\
T_{\beta}=\text { MNDWI }
\end{gathered}
$$

among which, $X_{3}$ and $X_{7}$ are the green bands and short-wave infrared band, respectively.

Because of the influence of the ice and cloud contained in images of different periods, the threshold range of water extraction was determined by combining image histogram and the visual interpretation results with the algorithm based on the water index model. The corresponding threshold range of each image is shown in Table 4.

Table 4. The corresponding threshold of images.

\begin{tabular}{ccccc}
\hline \multirow{2}{*}{ Year } & \multicolumn{2}{c}{ Drought Season } & \multicolumn{2}{c}{ Wet Season } \\
& Specific Time & Threshold & \multicolumn{2}{c}{$T=\left(\boldsymbol{X}_{\mathbf{4}}+\boldsymbol{X}_{\mathbf{5}}+\boldsymbol{X}_{\mathbf{7}}\right)-\boldsymbol{X}_{\mathbf{3}}-\boldsymbol{X}_{\mathbf{2}}$} \\
& Specific Time & Threshold \\
\hline 1988 & 5 January 1988 & $03<\mathrm{Tw}<0.9$ & 28 May 1988 & \\
1993 & 2 January 1993 & $0.3<\mathrm{Tw}<1$ & 29 July 1993 & \\
1998 & 6 April 1998 & $0<\mathrm{Tw}<1$ & 2 February 1998 & \\
2003 & 19 March 2003 & Tw $>0.38$ & 16 July 2003 & Ts $<0$ \\
2008 & 13 February 2008 & Tw $>0.84$ & 13 July 2008 & \\
2013 & 18 February 2013 & Tw $>0.73$ & 4 July 2013 & \\
2018 & 23 January 2018 & Tw $>0.84$ and & 9 July 2018 & \\
& & $1<\mathrm{Tw}<0$ & & \\
\hline
\end{tabular}

\subsubsection{Threshold Segmentation}

The threshold $T$ based on the index model was taken as the standard of segmentation. Any pixel $f(x, y)$ that satisfied the format of $f(x, y) \geq T$ was regarded as target points, while others were regarded as background points [23,52]. Therefore, the image processed with the threshold $T$ as a segmentation criterion can be defined as:

$$
g(x, y)= \begin{cases}1 & f(x, y) \geq T \\ 0 & f(x, y)<T\end{cases}
$$


among which a pixel with the label of 1 was target water, a pixel with the label of 0 was background, as non-aqueous part. Based on the threshold segmentation algorithm, we split images into target water and background. The result is shown in Figure 4.

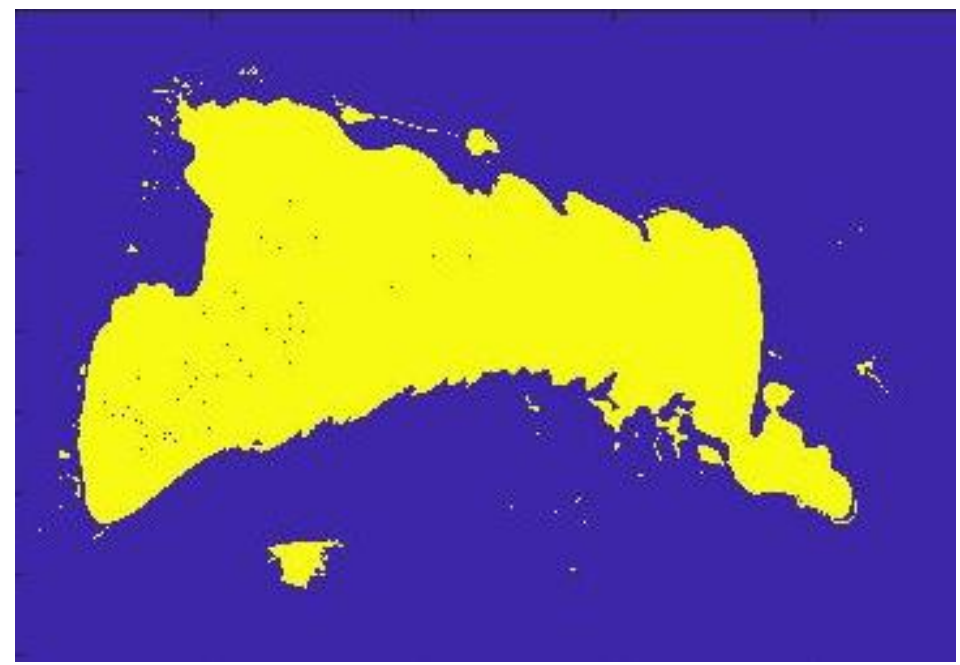

Figure 4. The initial result of threshold segmentation (28 May 1988).

\subsubsection{Median Filter}

For the noise problem existing in a binary image extracted by the threshold segmentation algorithm, this study selected the median filter [43] and the open-close algorithm [44-48] to achieve noise removal. The median filter was a nonlinear signal processing technique that was used to reduce noise effectively based on sorting statistical theory [43]. Its basic principle is that the intermediate value is replaced by the digital value of one point or the neighboring value of point in a sequence of numbers, thereby eliminating isolated noise points by making the surrounding pixel values closing to true value. In this way, it was able to reduce or remove the high frequency components in Fourier Space as the high frequency components correspond to the gray value of margin of images in a region, which had relatively large changes so that it can be filtered and the image can be smoothed, although with a little bit influence to low frequency components.

The output of two-dimensional median filter is:

$$
g(x, y)=\operatorname{mid}\{f(x-K, y-I),(K, I \in W)\}
$$

among which $f(x, y)$ indicates the original image and $g(x, y)$ demonstrates the processed image. $W$ is a 2-dimensional template. This algorithm not only preserved the information of image margins, but also smoothed the noise generated from image segmentation.

\subsubsection{Open-Close Algorithm}

The information processed by the open algorithm and close algorithm were related to the convex and concave of portions of images respectively, so, they both belonged to one-side operators [44-48]. The small holes that cannot be removed by a median filter were able to be filtered based on open-close algorithm operators, and we compared the results of direct opening, direct closing, first opening and then closing, first closing and then opening. It suggested that the procedure of first closing and then opening performed the best, removing the small spot and filling the small holes in a target area, achieving the purpose of smoothing the outside margin of images. The result is shown as Figure 5. 


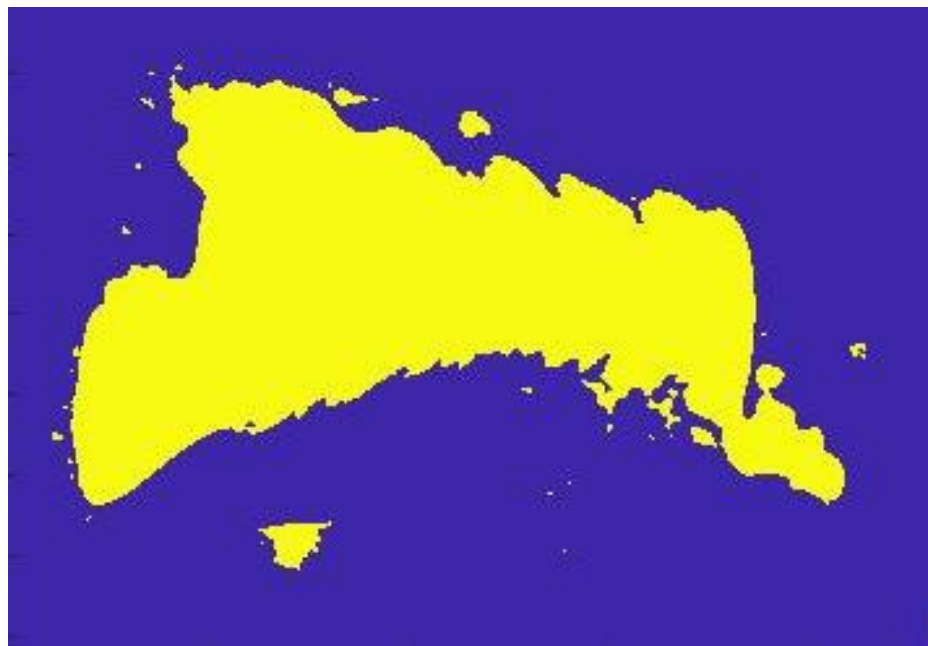

Figure 5. The result of open-closing algorithm (28 May 1988).

\section{Results}

\subsection{Area Extraction of the Bosten Lake}

\subsubsection{Results of Water Information Extraction}

The water was extracted by binarization using reclassification of an outputted binary graph from a threshold segmentation algorithm. Meanwhile, with the help of visual verification, non-removed lake debris and noise can be removed successfully, thus obtaining the vector area of Bosten Lake. The extraction results of drought season and wet season are shown as Figures 6 and 7.
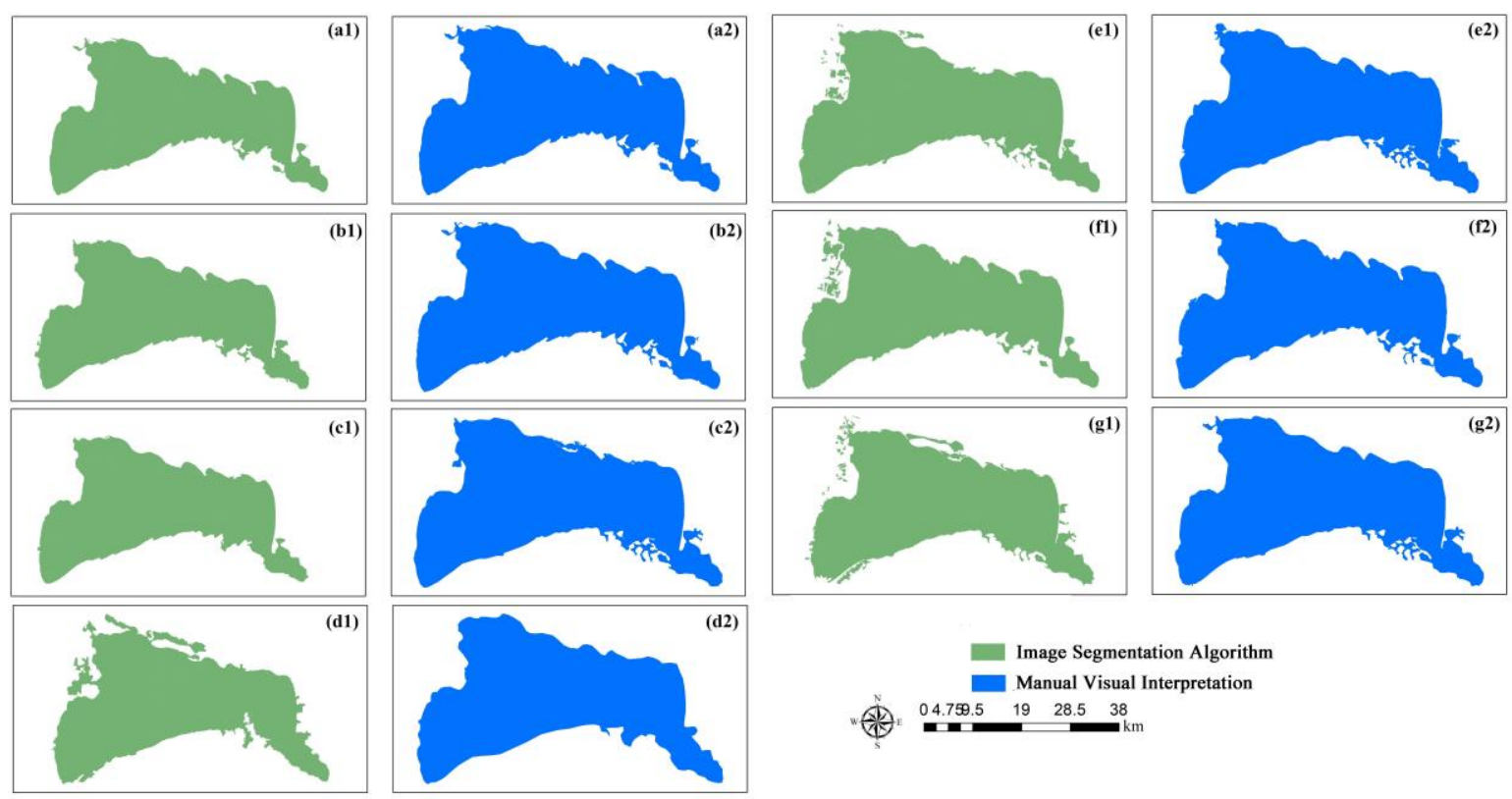

Figure 6. The extraction results of Bosten Lake in drought season using global threshold segmentation and artificial visual interpretation. (a) 5 January 1988, (b) 2 January 1993, (c) 6 April 1998, (d) 19 March 2003, (e) 18 February 2008, (f) 18 February 2013, (g) 23 January 2018. 

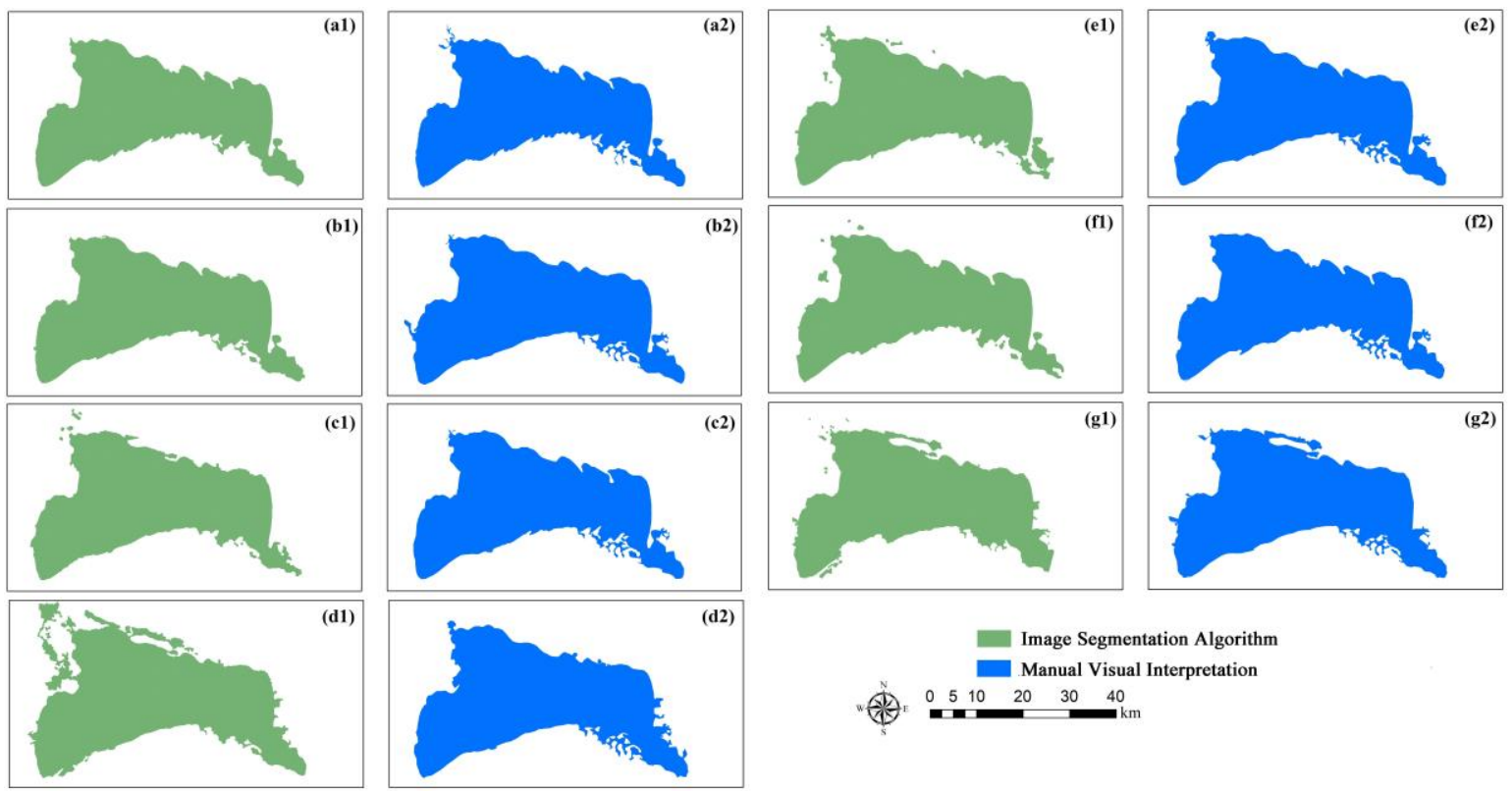

Figure 7. The extraction results of Bosten Lake in wet season using global threshold segmentation and artificial visual interpretation. (a) 28 May 1988, (b) 29 July 1993, (c) 2 July 1998, (d) 16 July 2003, (e) 13 July 2008, (f) 4 July 2013, (g) 9 July 2018.

\subsubsection{Analysis of Water Area Extraction Accuracy}

Because of the accuracy problem of water extraction, this paper selected two ways to process 14 images in 1988, 1993, 1998, 2003, 2008, 2013, and 2018, and evaluated the reliability of the research dataset: (1) Segmentation method based on global threshold of images and (2) artificial visual interpretation method. The detailed information of the area extracted by these two methods as well as their difference and percentage are shown as Table 5.

Table 5. The comparison between the results of two extraction methods (unit is $\mathrm{km}^{2}$ ).

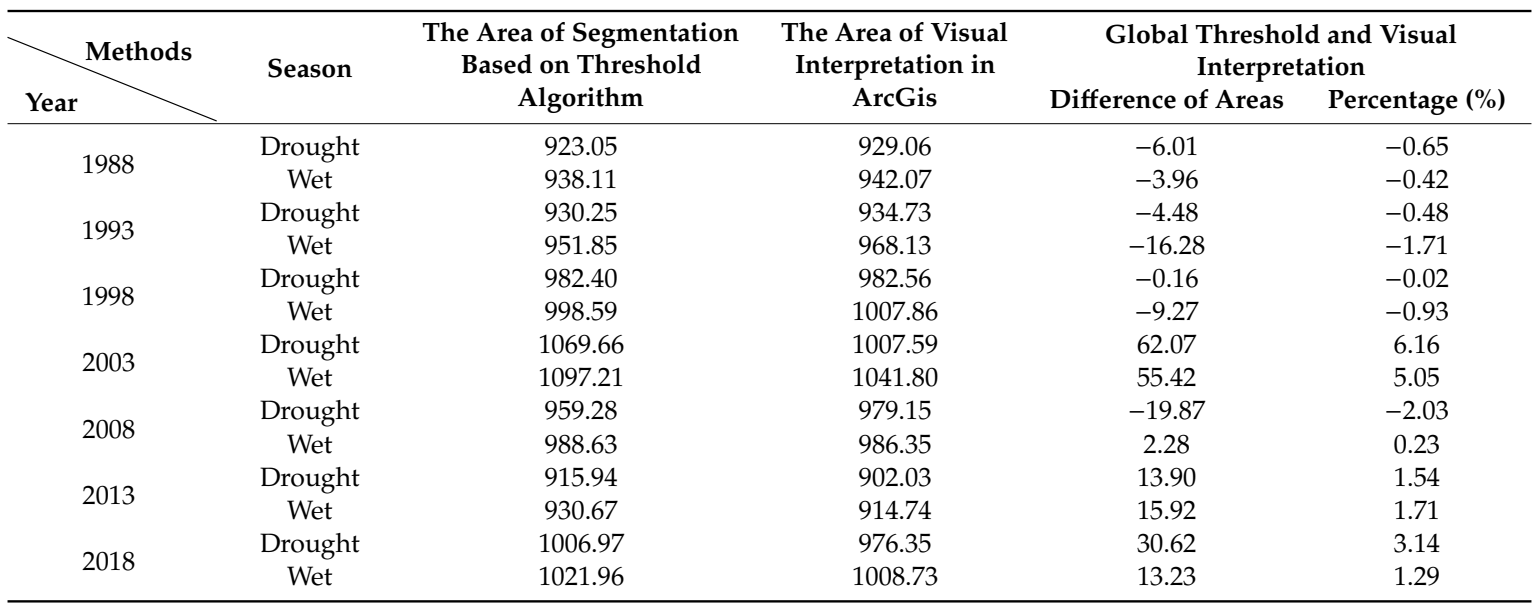

As shown in Table 5, the biggest areal difference between global threshold segmentation and artificial visual interpretation was $62.07 \mathrm{~km}^{2}$, while the smallest was $0.16 \mathrm{~km}^{2}$. The percentages were all lower than $10 \%$, with the highest value of $6.16 \%$ and the lowest value of $0.02 \%$. This proved that the global threshold segmentation employed in this paper can meet the demand for acceptable accuracy. 


\subsubsection{Summary of Water Surface Area of the Bosten Lake from 1988 to 2018}

Closed operation and open operation were utilized, respectively, to remove noise in the water area and then output binary images. After that, we built a time series of water area in drought season and wet season separately. Their values were counted as shown in Table 6.

Table 6. The area of Bosten Lake extracted by global threshold segmentation.

\begin{tabular}{ccccc}
\hline \multirow{2}{*}{ Year } & \multicolumn{2}{c}{ Drought Season } & \multicolumn{2}{c}{ Wet Season } \\
& Specific Time & Area $\left.\mathbf{( k m}^{\mathbf{2}}\right)$ & Specific Time & Area $\left.\mathbf{( k m}^{\mathbf{2}}\right)$ \\
\hline 1988 & 5 January 1988 & 923.05 & 28 May 1988 & 938.11 \\
1993 & 2 January 1993 & 930.25 & 29 July 1993 & 951.85 \\
1998 & 6 April 1998 & 982.40 & 2 July 1998 & 998.59 \\
2003 & 19 March 2003 & 1069.66 & 16 July 2003 & 1097.21 \\
2008 & 13 February 2008 & 959.28 & 13 July 2008 & 988.63 \\
2013 & 18 February 2013 & 915.94 & 4 July 2013 & 930.67 \\
2018 & 23 January 2018 & 1006.97 & 9 July 2018 & 1021.96 \\
\hline
\end{tabular}

\subsection{Analysis of Area Dynamic Changes in Bosten Lake}

\subsubsection{Research Index Extraction}

For the influence of snow and ice content and other objects in images of different phases, this article respectively analyzes the area dynamic changes of Bosten Lake during drought season and wet season in the recent 30 years and analyzes the change characteristics of lake area primarily according to annual dynamics in 30 years. To analyze better and more intuitively, annual area change amount $A a\left(\mathrm{~km}^{2}\right)$ and annual area change rate Aar (\%) are selected as two indicators to describe the change situation. The equations of the two indicators are as follow:

$$
\begin{gathered}
A_{a}=\text { Area }_{\text {yuarly }}-\text { Area }_{\text {mean }} \\
\text { Aar }=\frac{A a}{\text { Area }_{\text {mean }}}
\end{gathered}
$$

among which, $A a$ (area anomaly) denotes area change amount, Area yearly $_{\text {and }}$ Area $a_{\text {mean }}$ denote the lake area in one year from 1988 to 2018 and the average lake area in 30 years, and Aar (area anomaly rate) denotes the area change rate.

The area change indicators of Bosten Lake during 30 years, $A a$ and Aar, are calculated using the above equations, and have been summarized in Table 7.

Table 7. Indicators of area dynamic changes of Bosten Lake.

\begin{tabular}{cccccc}
\hline \multicolumn{2}{c}{ Year } & Yearly Area $\left.\mathbf{( k m}^{\mathbf{2}}\right)$ & Mean Area $\left.\mathbf{( k m}^{\mathbf{2}}\right)$ & $\boldsymbol{A a} \mathbf{( \mathbf { k m } ^ { \mathbf { 2 } } )}$ & Aar $\mathbf{( \% )}$ \\
\hline \multirow{2}{*}{1988} & Drought & 923.05 & 969.65 & -46.60 & -4.81 \\
& Wet & 938.11 & 989.57 & -51.46 & -5.20 \\
\multirow{2}{*}{1993} & Drought & 930.25 & 969.65 & -39.40 & -4.06 \\
& Wet & 951.85 & 989.57 & -37.72 & -3.81 \\
\multirow{2}{*}{1998} & Drought & 982.40 & 969.65 & 12.75 & 1.32 \\
& Wet & 998.59 & 989.57 & 9.02 & 0.91 \\
\multirow{2}{*}{2003} & Drought & 1069.66 & 969.65 & 100.01 & 10.31 \\
& Wet & 1097.21 & 989.57 & 107.64 & 10.88 \\
\multirow{2}{*}{2008} & Drought & 959.28 & 969.65 & -10.37 & -1.07 \\
& Wet & 988.63 & 989.57 & -0.94 & -0.10 \\
& Drought & 915.94 & 969.65 & -53.71 & -5.54 \\
& Wet & 930.67 & 989.57 & -58.90 & -5.95 \\
& Drought & 1006.97 & 969.65 & 37.32 & 3.85 \\
& Wet & 1021.96 & 989.57 & 32.39 & 3.27 \\
\hline
\end{tabular}

$A a$-area anomaly; Aar-area anomaly rate. 


\subsubsection{Characteristics of Area Changes in Drought Season}

As indicated in Figure 8, the average area of Bosten Lake in the drought season was $969.65 \mathrm{~km}^{2}$. The lake area peaked in 2003 with a value of $1069.66 \mathrm{~km}^{2}$ and went down to the lowest in 2013 with a value of $915.94 \mathrm{~km}^{2}$. These two years were also the turning points in area dynamics over the last 30 years. They divide the changing trend of the area into three distinct stages.

1. From 1988 to 2003, the area of Bosten Lake in drought season showed a rising trend and the average area of the lake in these 15 years was $976.34 \mathrm{~km}^{2}$. From $923.05 \mathrm{~km}^{2}$ in 1988 to $1069.66 \mathrm{~km}^{2}$ in 2003 , it increased by $146.61 \mathrm{~km}^{2}$ in 15 years, with an average annual change rate of $9.77 / \mathrm{a}$ and an increase of $15.88 \%$ and reached the historical maximum of $1069.66 \mathrm{~km}^{2}$ in 2003 .

2. From 2003 to 2013, the area of Bosten Lake in drought season showed a declining trend and the average area of the lake in these 10 years was $981.62 \mathrm{~km}^{2}$. From $1069.66 \mathrm{~km}^{2}$ in 2003 to $915.94 \mathrm{~km}^{2}$ in 2013, it decreased by $153.72 \mathrm{~km}^{2}$ in 10 years, with an average annual change rate of $-16.65 / \mathrm{a}$ and a decrease of $14.37 \%$ and reached the historical minimum of $915.94 \mathrm{~km}^{2}$ in 2013 .

3. From 2013 to 2018, the area of Bosten Lake in drought season showed a rising trend and the average area of the lake in these 5 years was $961.45 \mathrm{~km}^{2}$. From $915.94 \mathrm{~km}^{2}$ in 2013 to $1006.97 \mathrm{~km}^{2}$ in 2018 , it increased by $91.03 \mathrm{~km}^{2}$ in 5 years, with an average annual change rate of 18.21/a and an increase of $9.94 \%$.

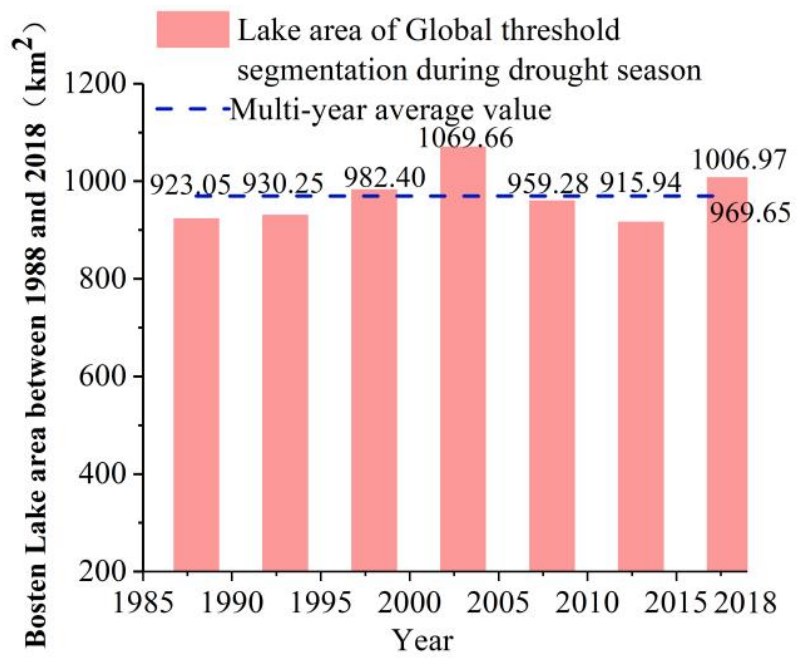

Figure 8. Area of Bosten Lake in drought season from 1988 to 2018.

\subsubsection{The Characteristics of Area Change in the Wet Season}

As indicated in Figure 9, the average area of Bosten Lake in the wet season was $989.57 \mathrm{~km}^{2}$. The lake area peaked in 2003 with a value of $1097.21 \mathrm{~km}^{2}$ and went down to the lowest in 2013 with a value of $930.67 \mathrm{~km}^{2}$. These two years were also the turning points in area dynamics over the last 30 years, and they divide the changing trend of the area into three distinct stages.

1. From 1988 to 2003, the area of Bosten Lake in drought season shown rise trend, and the average area of the lake in these 15 years was $996.44 \mathrm{~km}^{2}$. From $938.11 \mathrm{~km}^{2}$ in 1988 to $1097.21 \mathrm{~km}^{2}$ in 2003 , it increased by $159.10 \mathrm{~km}^{2}$ in 15 years, with an average annual change rate of 10.61/a and an increase of $16.96 \%$ and reaching the historical maximum of $1097.21 \mathrm{~km}^{2}$ in 2003.

2. From 2003 to 2013 , the area of Bosten Lake in drought season showed a declining trend, and the average area of the lake in these 10 years was $1005.50 \mathrm{~km}^{2}$. From $1097.21 \mathrm{~km}^{2}$ in 2003 to $930.67 \mathrm{~km}^{2}$ in 2013 , it decreased by $166.54 \mathrm{~km}^{2}$ in 10 years, with an average annual change rate of $-15.37 / \mathrm{a}$ and a decrease of $15.18 \%$ and reached the historical minimum of $930.67 \mathrm{~km}^{2}$ in 2013 . 
3. From 2013 to 2018, the area of Bosten Lake in drought season showed a rising trend, and the average area of the lake in these 5 years was $976.31 \mathrm{~km}^{2}$. From $930.67 \mathrm{~km}^{2}$ in 2013 to $1021.96 \mathrm{~km}^{2}$ in 2018, it increased by $91.29 \mathrm{~km}^{2}$ in 5 years, with an average annual change rate of $18.26 / \mathrm{a}$ and an increase of $9.81 \%$.

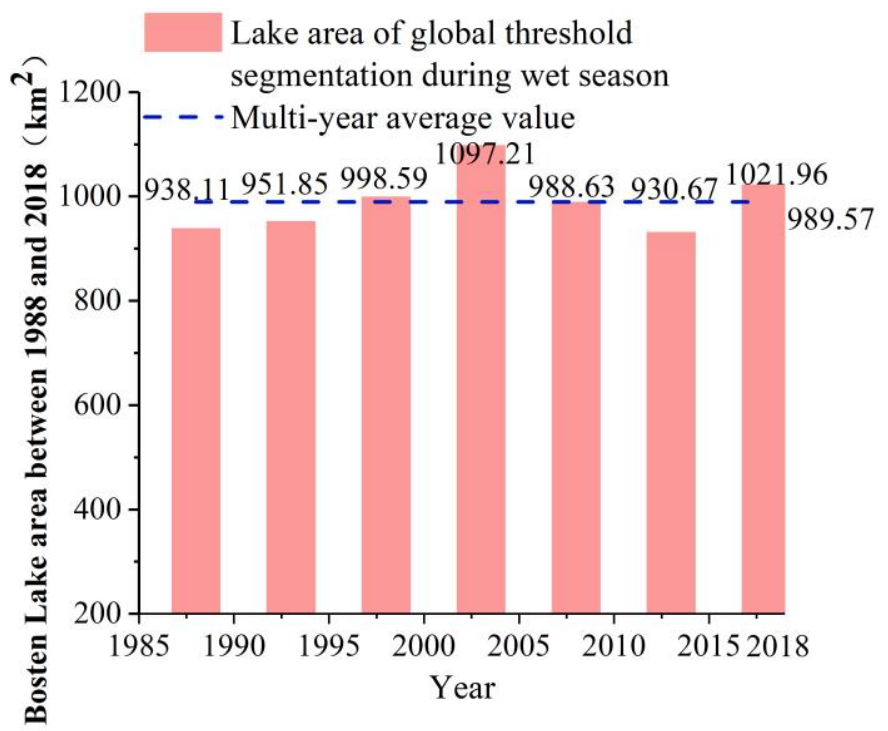

Figure 9. Statistics of Bosten Lake area of the wet season in 1988-2018.

\subsubsection{Variation Characteristics of Lake Shoreline}

In the past 30 years, the area of Bosten Lake was mainly changed in local regions, such as Huangshuinao Village, NanshaLiang Village, and Ba'aobicun Village (Figure 10a). The lake boundary showed an overall rise-resolved slow-recovery trend in the three regions based on the lake in 1988 . The lake in the Huangshuinao Village expanded to the junction of the village and the lake until 2003. After 2013, the lake obviously subsided from the village boundary to the main part of the lake. While by 2018 , the lake boundary was slowly expanding to the village boundary (Figure 10b). In the Nansha Liangcun area, the lake shoreline expanded from the main body of the lake in 1988 to the village boundary area until 2013. After 2013, the coastline retreated back to the main area of the lake in 2013. By 2018, the northward shoreline of the area faded significantly. The southwestern shoreline rebounded in a small area, and the lake shoreline slowly recovered (Figure 10c). The shoreline change of the lakes in the Baqiu Bicun village area was relatively stable. Based on 1988, the coastline change was the most obvious in 2003, and the coastline rose to the largest area. In 2013, the shoreline slowly declined to the edge of the village boundary. By 2018, the change of lake shoreline had become small (Figure 10c). 


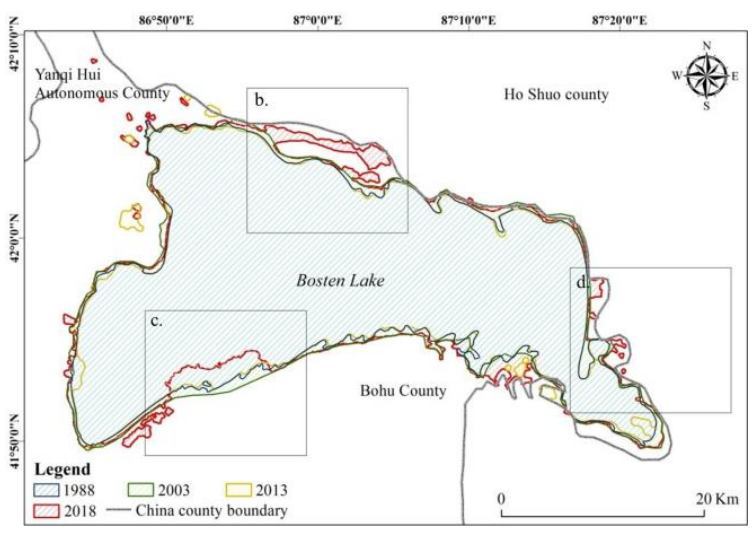

(a)
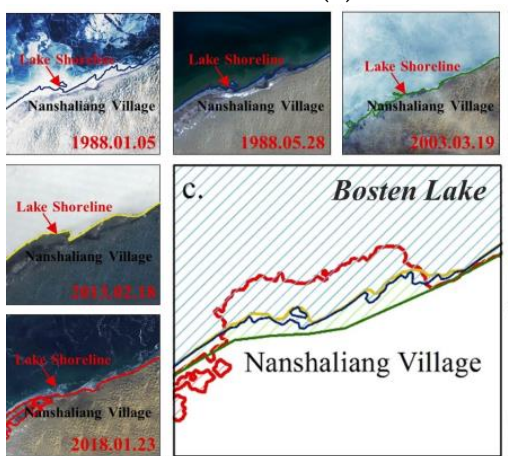

(c)

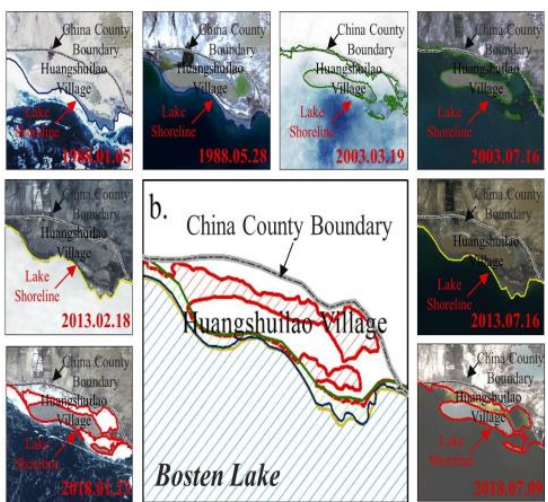

(b)
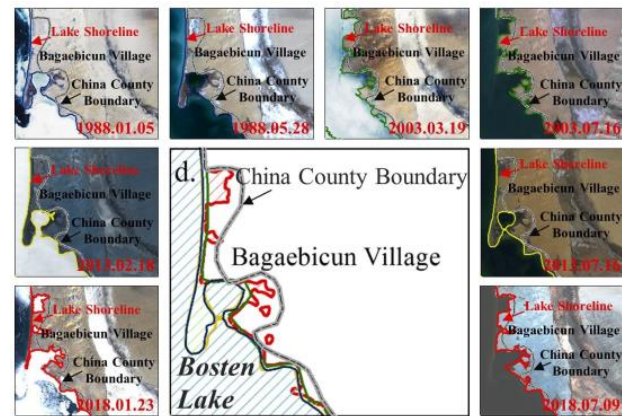

(d)

Figure 10. The shoreline transition of the Bosten Lake in 1988-2018 (shoreline changes for all years are based on the shoreline in 1988). (a) Bosten Lake shoreline change, (b) Huangshuila Village shoreline change, (c) Nanshaliang Village shoreline change, (d) Bagaebicun Village shoreline change.

\subsection{Extraction of Climate Change Assessment Factors in Bosten Lake Basin}

This paper mainly discusses the climate changes from annual dynamics. We summarized six factors, including precipitation, average temperature, evaporation, relative humidity, average wind speed, and sunshine hours observed from five meteorological stations in Bosten Lake Basin, like Figure 11.

We analyzed the characteristics of climate changes and their correlations in the recent 30 years on the basis of annual average value and an average value of each meteorological factor in drought season and wet season. The annual average values and corresponding mean areas are shown in Table 8.

Table 8. Meteorological factor values of Bosten Lake in recent 30 years.

\begin{tabular}{|c|c|c|c|c|c|c|c|}
\hline Year & $\begin{array}{c}\text { Area } \\
\left(\mathrm{km}^{2}\right)\end{array}$ & $\begin{array}{l}\text { Precipitation } \\
(\mathbf{m m})\end{array}$ & $\begin{array}{c}\text { Average } \\
\text { Temperature } \\
\left({ }^{\circ} \mathrm{C}\right)\end{array}$ & $\begin{array}{l}\text { Evaporation } \\
(\mathrm{mm})\end{array}$ & $\begin{array}{c}\text { Relative } \\
\text { Humidity } \\
(\%)\end{array}$ & $\begin{array}{l}\text { Sunshine } \\
\text { Hours (h) }\end{array}$ & $\begin{array}{c}\text { Average } \\
\text { Wind Speed } \\
(\mathrm{m} / \mathrm{s})\end{array}$ \\
\hline 1993 & 941.05 & 86.38 & 10.07 & 1803.48 & 55.41 & 2835.47 & 1.8 \\
\hline 1998 & 990.50 & 111.74 & 9.56 & 1513.42 & 57.63 & 2816.79 & 1.5 \\
\hline 2003 & 1083.44 & 121.7 & 8.97 & 1494.52 & 56.71 & 2704.39 & 1.89 \\
\hline 2013 & 923.30 & 60.19 & 10.64 & 2246.87 & 53.58 & 2954.72 & 1.55 \\
\hline 2018 & 1014.46 & 79.58 & 9.35 & 1561.9 & 56.5 & 2797.15 & 1.87 \\
\hline
\end{tabular}




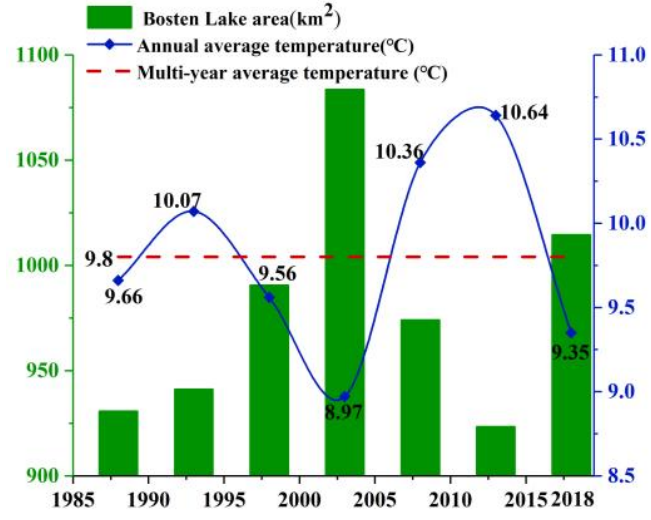

(a)

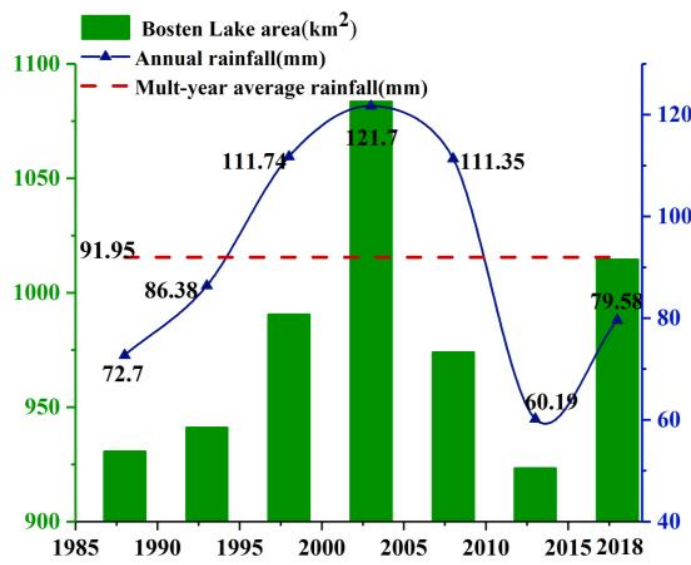

(c)

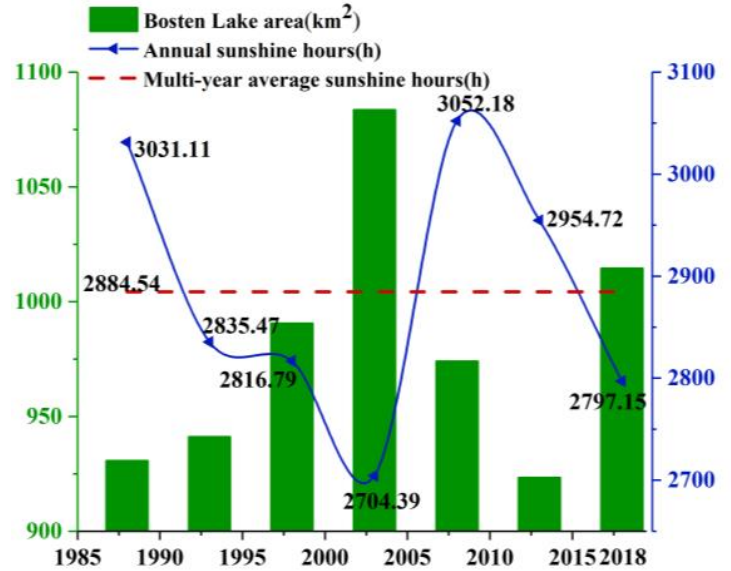

(e)

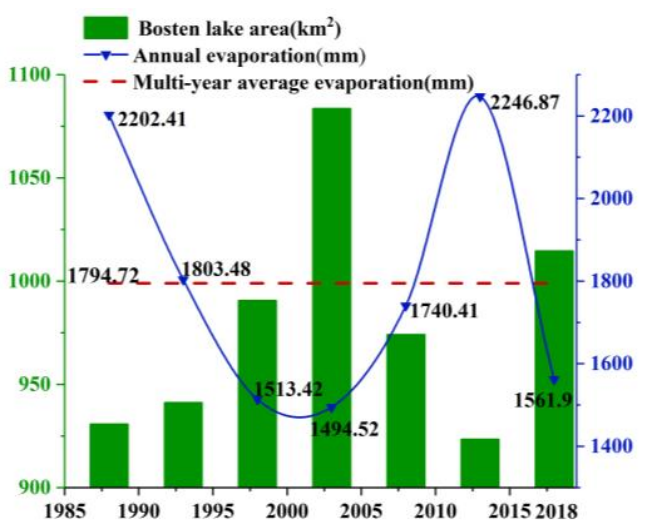

(b)

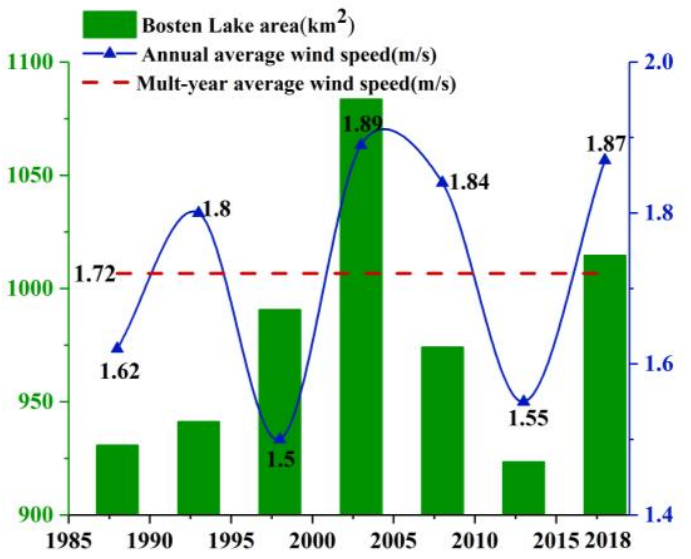

(d)

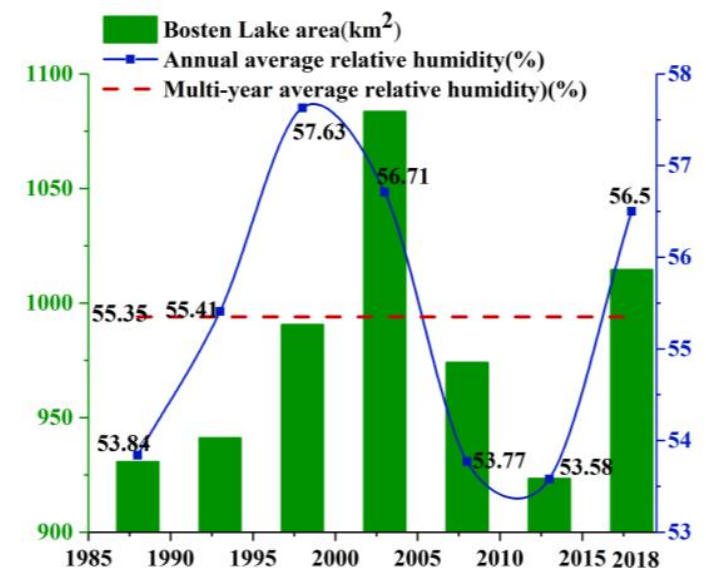

(f)

Figure 11. The changes of meteorological factors in Bosten Lake from 1988 to 2018. (a) Indicates the changes in the drivers (Annual average temperature and Multi-year average temperature) of the Bosten Lake area change; (b) indicates the changes in the drivers (Annual evaporation and Multi-year average evaporation) of the Bosten Lake area change; (c) indicates the hanges in the drivers (Annual rainfall and Multi-year average rainfall) of the Bosten Lake are change; (d) indicates the changes in the drivers (Annual average wind speed and Multi-year average wind speed) of the Bosten Lake area change; (e) indicates the changes in the drivers (Annual sunshine hours and Multi-year average sunshine hours) of the Bosten Lake area change; (f) indicates the changes in the drivers (Annual average relative humidty and Multi-year average relative humidty) of the Bosten Lake area change. 


\subsection{Dynamic Change of Bosten Lake Area and Response to Climate Change}

Based on the climate change assessment factors and lake area of the Bosten Lake from 1988 to 2018, this paper adopted the linear regression model to realize the response of dynamic changes of the lake area and climate change. The correlation coefficient $\mathrm{R}^{2}$ was mainly used to measure whether the correlation was significant. The higher the correlation coefficient $\mathrm{R}^{2}$, the higher the correlation, and vice versa. As shown in Table 9, the correlation between each meteorological factor and area change was analyzed by the linear regression model. Among which, climate change assessment factors and correlation factors of lake area were that annual average precipitation Pearson's $r=0.73, R^{2}=0.53$, indicating medium correlation; annual average temperature Pearson's $r=-0.8, R^{2}=0.63$, indicating relatively strong correlation; annual average evaporation Pearson's $r=-0.82, R^{2}=0.67$, indicating the strongest correlation; annual average relative humidity Pearson's $r=0.69, R^{2}=0.48$, indicating relatively weak correlation; annual average wind speed Pearson's $r=-0.56, R^{2}=0.32$, indicating the weak correlation; annual average sunshine hours Pearson's $r=-0.74, R^{2}=0.55$, indicating medium correlation. Therefore, we can conclude that the order of significance of the meteorological factor was annual average evaporation $>$ average temperature $>$ annual average sunshine duration $>$ annual average precipitation $>$ annual average relative humidity $>$ annual average wind speed.

Table 9. The correlation between area changes and meteorological factors.

\begin{tabular}{cccc}
\hline Meteorological Factors & Pearson's r & $\mathbf{R}^{\mathbf{2}}$ & Linear Equation \\
\hline Annual average precipitation $(\mathrm{mm})$ & 0.73 & 0.53 & $y=1.77547 x+816.35939$ \\
Annual average temperature $\left({ }^{\circ} \mathrm{C}\right)$ & -0.8 & 0.63 & $y=-76.91227 x+1733.46154$ \\
Annual average evaporation $(\mathrm{mm})$ & -0.82 & 0.67 & $y=-0.14708 x+1243.58041$ \\
Annual average relative humidity $(\%)$ & 0.69 & 0.48 & $y=23.73255 x-333.95157$ \\
Annual average wind speed $(\mathrm{m} / \mathrm{s})$ & 0.56 & 0.32 & $y=195.73431 x+642.10955$ \\
Annual average sunshine hours $(\mathrm{h})$ & -0.74 & 0.55 & $y=-0.32168 x+1907.52442$ \\
\hline
\end{tabular}

\section{Discussion}

1. Water surface area extraction methods: After comparing the single-band threshold method and multi-band spectral relationship method to solve the accuracy problem of water information extraction, this article selected NDWI and MNDWI as the threshold-based image segmentation algorithm based on the characteristics of large Bosten Lake injection and outflow, under the help of noise removing using mathematical morphology operator, i.e., opening and closing operations. We extracted water surface area from 14 images and evaluated the accuracy by comparing it with the water area extracted from the manual visual interpretation method. The highest area difference between the results of global threshold segmentation and artificial visual interpretation was $62.07 \mathrm{~km}^{2}$, the lowest was $0.16 \mathrm{~km}^{2}$. All percentages of the extracted area were less than $10 \%$, with the highest value of $6.16 \%$ and the lowest value of $0.02 \%$. The idea behind the proposed method was that the water index can effectively reduce the impacts of other objects and the threshold method can change the extraction algorithm according to the difference of images in various phases to ensure data accuracy. In this way, water information would be quickly and effectively extracted compared with other methods. The long-term monitoring of the changes in the Bosten Lake from high-resolution remote sensing images is lacking. Liu et al. [53] used $1.1 \mathrm{~km}$ resolution National Oceanic and Atmospheric Administration/Advanced Very High Resolution Radiometer (NOAA/AVHRR) images in 2006 to investigate the dynamics of water surface area of the Bosten Lake from 1990 to 1998. They found that the lake area increased significantly during that period. Their study only investigated the changes in the lake area of 8 years. Ayinur et al. [54] quantified the areas of the Bosten Lake in 1978, 1990, 2000, and 2015, respectively, and found a decrease from 1978 to 1990, an increase from 1990 to 2000 followed by a decrease from 2000 to 2015. Although they provided a long-time investigation, the low temporal resolution of their study could not explain the continuous changing trend during the time period they selected [54]. 
Sun et al. [29] used Landsat images to investigate the dynamics of Bosten Lake and found an increase from 1988 to 2002 followed by a decrease from 2002 to 2014. Yao et al. [55] compiled remote sensing images and inventory data to reconstruct the surface area of Bosten Lake from 1961 to 1987. They found a significant decrease from 1961 to 1987, a substantial increase from 1988 to 2002, a decrease from 2003 to 2012, and an increase from 2013 to 2016 [55]. Although they provide a long-time and comprehensive investigation, their study was still limited by the lacking of considering seasonal variation. Due to the typical continental climate condition of the Bosten Lake, the lake has high hydraulic loading and short residence time. We, therefore, investigated the spatial-temporal pattern of water surface area of the Bosten Lake in the dry season and rainy season separately. This study provided the estimation of the surface area of Bosten Lake with the highest spatial and temporal resolution. The noticeable seasonal variations of lake water surface area enhancing the idea that the changes in lake surface area were mostly governed by climate forcing.

2. Bosten Lake is located in Bengbu Basin which is between the desert and the mountains. The mountainous topographic surface results in the special lake climate in the local region. As global warming worsens, the water cycle process is becoming gradually better, and various factors have made climate change in the study area more complicated. As a result, considering that Bosten Lake area is relatively large and it is needed to reflect the climatic conditions in different regions of the basin and the whole region, respectively, this paper set five meteorological stations as representative, i.e., Hejing, Yanqi, Heshuo, Yuli and Korla stations, and analyzed the climate change characteristics of Bosten Lake Basin from six factors, i.e., precipitation, average temperature, evaporation, relative humidity, average wind speed, and sunshine hours. As indicated in previous research, the area changes of Bosten Lake Basin mainly related to human social and economic activities and climate changes, but the correlation of lake area changes and these two factors was different. Climate played a more significant role in lake area changes than human behaviors, and the temperature, rainfall, evaporation, sunshine hours, average wind speed, and relative humidity had the most significant impact on the lake among plenty of climate-related factors. Thus, the major focus in this study was the response between lake dynamics and climate change in the study area derived from meteorological factors. But it was necessary to keep in mind that each meteorological factor was only one of the reasons that caused the dynamic changes of the lake area because as a travel set, Bosten Lake has a large floating population, and the influence of human behaviors was inevitable.

3. In recent years, the development of monitoring lake dynamic changes with remote sensing technology is becoming gradually better. But there were still some challenges as lakes vary in size and variety and lakes in different seasons will have different forms due to icing, precipitation, etc.

a. Lakes distribute all over the world and their areas are naturally inconsistent. For example, the area of Bosten Lake, which is the largest inland lake, is more than $4000 \mathrm{~km}^{2}$ while areas of some small lakes are less than $1 \mathrm{~km}^{2}$. Moreover, the resolution difference and scale effect of the image will directly affect the extraction result of the lake area, which will cause errors in the monitoring process. When the lake area is small, there will be a mixed pixel phenomenon in the area extraction process with uncertainty. Besides, the cloud coverage in optical images can cause great difficulties in lake area extraction. Therefore, this paper selected Landsat long time series data with high resolution and based on the threshold image segmentation algorithm combined with visual interpretation verification to ensure the accuracy of area extraction.

b. Lake water systems are also easy to change as the seasons change. In summer, the temperature is high and the lake area would be large, while in winter, the temperature is low and the lake would be covered by ice and snow for a long time. As a consequence, the lake area extraction should not only consider the lake range in the normal state but also 
consider the lake range during the snow and ice period. Therefore, this paper monitored the dynamic change of lake area based on the comparison of two groups of data in the dry season and the ice-free period.

\section{Conclusions}

In this paper, the area changes in Bosten Lake, the largest inland lake in China, were investigated. Based on remote sensing data, meteorological data, lake vector data, administrative division data, and socio-economic data, water information extraction, area dynamic changes, and climate changes and its correlation with area changes were conducted.

The main research results are as follows:

1. Water extraction methods: Landsat TM/ETM+/OLI images were employed as the main data source. After comparing the single-band threshold method and multi-band spectral relationship method, with the purpose of solving the accuracy problem of water information extraction, this article selected NDWI and MNDWI as the threshold-based image segmentation algorithm on the basis of the characteristics of large Bosten Lake injection and outflow. Under the help of noise removal using mathematical morphology operator, i.e., opening and closing operations, we extracted water information from 14 images and evaluated the accuracy by comparing with the water area extracted from the manual visual interpretation method. The highest area difference between the results of global threshold segmentation and artificial visual interpretation was 62.07 $\mathrm{km}^{2}$, the lowest was $0.16 \mathrm{~km}^{2}$. All percentages of the extracted area were less than $10 \%$, with the highest value of $6.16 \%$ and the lowest value of $0.02 \%$. The idea behind the proposed method was that the water index can effectively reduce the impacts of other objects and the threshold method can change the extraction algorithm according to the difference of images in various phases to ensure data accuracy. In this way, water information would be quickly and effectively extracted compared with other methods.

2. Area dynamic change characteristics: Because of the influence of ice and snow content and other features on different time-phase images, this paper took two sets of data of drought season and wet season in 1988, 1993, 1998, 2003, 2008, 2013, and 2018 as examples to analyze the area dynamic changes of Bosten Lake in the past 30 years. Between 1988 and 2018, the overall change of lake area fluctuated greatly, showing a trend from fluctuation to significant decline and overall increase. Among which, 2003 and 2013 were two turning points in area changes, dividing the trend of lake area changes into three obvious periods:

a. From 1988 to 2003, the area of Bosten Lake in drought and wet season rose and the average area of the lake in these 15 years were $976.34 \mathrm{~km}^{2}$ and $996.44 \mathrm{~km}^{2}$, respectively, with an average annual change rate of 9.77/a and 10.61/a, and reached the historical maximum of $1069.66 \mathrm{~km}^{2}$ and $1097.21 \mathrm{~km}^{2}$ in 2003.

b. From 2003 to 2013, the area of Bosten Lake in drought season and wet season both declined and the average area of lake in these 10 years was $981.62 \mathrm{~km}^{2}$ and $1005.50 \mathrm{~km}^{2}$, respectively, with an average annual change rate of $-16.65 / \mathrm{a}$ and $-15.37 / \mathrm{a}$, and reached the historical minimum of $915.94 \mathrm{~km}^{2}$ and $930.67 \mathrm{~km}^{2}$ in 2013.

c. From 2013 to 2018, the area of Bosten Lake in drought season and wet season both rose and the average area of the lake in these 5 years was $961.45 \mathrm{~km}^{2}$ and $976.31 \mathrm{~km}^{2}$, respectively, with an average annual change rate of 18.21/a and 18.26/a.

3. Climate change and its response: Because climate plays a more significant role in the lake area changes than human behaviors, this study sets five meteorological stations as representative, i.e., Hejing, Yanqi, Heshuo, Yuli, and Korla stations, and selected the temperature, rainfall, evaporation, sunshine hours, average wind speed, and relative humidity from meteorological data of these five stations from 1988 to 2018 as assessment factors to analyze the characteristics of 
annual climate changes of Bosten Lake Basin in the past 30 years based on the six factors extracted by kriging interpolation. Also, we used a linear statistics method to analyze the correlation between the annual mean area and the annual mean value of climate factors. Results suggest that there was a large fluctuation in climate change of Bosten Lake Basin in the recent 30 years. The change trends of annual average evaporation, annual average temperature, annual average sunshine hours, and annual average wind speed were in contrast with the changing trend of the lake area, while the change trends of annual average precipitation and annual average relative humidity were almost consistent with the trend of the area change. Linear correlation between average annual mean area and meteorological factors showed that annual average precipitation $\mathrm{R}^{2}=0.53$, indicating medium correlation; annual average temperature $\mathrm{R}^{2}=0.63$, indicating relatively strong correlation; annual average evaporation $R^{2}=0.67$,indicating the strongest correlation; annual average relative humidity $\mathrm{R}^{2}=0.48$, indicating relatively weak correlation; annual average wind speed $R^{2}=0.32$,indicating the weak correlation; annual average sunshine hours $\mathrm{R}^{2}=0.55$,indicating medium correlation. The order of significance of meteorological factors could be concluded as: Annual average evaporation $>$ average temperature $>$ annual average sunshine duration $>$ annual average precipitation $>$ annual average relative humidity $>$ annual average wind speed.

4. This study provided the most comprehensive analysis with the highest spatial-temporal resolution remote sensing images. However, there are still several limitations throughout this work. (1) The meteorological data was hard to obtain, and five sites may not reflect the mountainous micro-climate in the study region. (2) We used different Landsat products (from Landsat 1 to Landsat 8). The quality of different satellites may influence the accuracy of the image classification. (3). We did not consider the effect of the melt of the local ice water and glacier, as well as the human disturbances which may slightly influence the attribution analysis of this study.

5. This study provided insight knowledge to support future water management relevant strategies. Since Bosten Lake is the major available freshwater resource to support the surrounding domestic and industry water consumption, all water allocations need to consistent with the goal of the local water management plan. Therefore, in future study, climate projections from Global Climate Models (GCMs) [56] of different emission scenarios need to be used to predict the changes in lake surface area in response to climate change.

Author Contributions: Conceptualization, X.D.; Data curation, X.Y.; Formal analysis, S.L.; Methodology, Y.G. and J.Z.; Writing —original draft, X.D. and X.Y.; Writing—review \& editing, X.D. and M.W. All authors have read and agreed to the published version of the manuscript.

Funding: This research was funded by the Key Project of Humanities and Social Sciences of Colleges and Universities of Sichuan Province (No. ZHYJ17-ZD01), the Scientific Innovation Team of Remote Sensing Science and Technology of Chengdu University of Technology (Grant No. KYTD201501), and the National Natural Science Foundation of China, remote sensing dynamic monitoring method for vegetation ecological water (layer) and water stress in the western Sichuan Plateau (No. 41671432).

Acknowledgments: The authors strongly appreciate the meteorological data provided by the Xinjiang Meteorological Center.

Conflicts of Interest: The authors declare no conflict of interest.

\section{References}

1. Thomas, B.F.; Famiglietti, J.S.; Landerer, F.W.; Wiese, D.N.; Molotch, N.P.; Argus, D.F. GRACE Groundwater Drought Index: Evaluation of California Central Valley groundwater drought. Remote Sens. Environ. 2017, 198, 384-392. [CrossRef]

2. Feng, Z.; Leung, L.R.; Hagos, S.; Houze, R.A.; Burleyson, C.D.; Balaguru, K. More frequent intense and long-lived storms dominate the springtime trend in central US rainfall. Nat. Commun. 2016, 7, 13429. [CrossRef] [PubMed] 
3. Zhang, Y.; Hai, M.; Yi, M.; Wei, B.; Ma, R.; Hong, B.; Wei, Y. Remote sensing analysis of the area change of Bosten Lake from 1972 to 2011. J. Anhui Agric. Sci. 2015, 43, 245-249.

4. Xie, M.; Liu, Z. Comparative study on water extraction methods based on multi-scale and multi-source remote sensing information. Inn. Mong. Sci. Technol. Econ. 2018, 8, 95-98.

5. Xu, R.; Zhang, Z.; Zhao, C. Comparative study on Remote Sensing Extraction Methods of lake water. Remote Sens. Inf. 2015, 30, 111-118.

6. Bartolucci, L.A.; Robinson, B.F.; Silva, L.F. Field measurements of the spectral response of natural waters. Photogramm. Eng. Remote Sens. 1977, 43, 595-598.

7. Shih, S.F. Comparison of ELAS classifications and density slicing Landsat data for water surface area assessment. Hydrol. Appl. Space Technol. 1985, 160, 91-97.

8. Horwitz, H.M.; Nalepka, R.F.; Hyde, P.D.; Morgenstern, J.P. Estimating the Proportions of objects within a single Resolution Element of a Multispectral scanner. In Proceedings of the 7th International Symposium on Remote Sensing of Environment, Ann Arbor, MI, USA, 17-21 May 1971; pp. 1307-1320.

9. McFeeters, S.K. The use of normalized difference water index (NDWI) in the delineation of open water features. Int. J. Remote Sens. 1996, 17, 1425-1432. [CrossRef]

10. $\mathrm{Xu}, \mathrm{H}$. Establishment of remote sensing water index from enhanced water index analysis. Earth Inf. Sci. 2008, 10, 776-780.

11. Mo, W.; Sun, H.; Zhong, S.; Huang, Y.; He, L. Study and application of MODIS water index model (CIWI). Remote Sens. Inf. 2007, 5, 16-21.

12. Yan, P.; Zhang, Y.; Zhang, Y. A Study on Information Extraction of Water System in Semi-arid Regions with the Enhanced Water Index (EWI) and GIS Based Noise Remove Techniques. Remote Sens. Inf. 2007, 6, 62-67.

13. Ding, F. Experimental study on water information extraction based on NWI. Sci. Surv. Mapp. 2009, 34, 155-157.

14. Lu, J. Application of multi temporal remote sensing data to analyze the influence of reclamation area in reservoir area. Remote Sens. Inf. 2001, 2, 35-40.

15. Su, F.; Gao, Y.; Zhou, C.; Yang, X.; Yun, F. Study on scale effect of China's land coastline. J. Geogr. Sci. 2011, 21, 1101-1111. [CrossRef]

16. Lin, C.; Li, S. Research progress in automatic extraction of water body from Landsat data. Tech. Autom. Appl. 2015, 34, 16-24.

17. Harris, A.R. Time series remote sensing of a climatically sensitive lake. Remote Sens. Environ. 1994, 50, 83-94. [CrossRef]

18. Birkett, C. The global remote sensing of lakes, wetlands and rivers for hydrological and climate research. In International Geoscience and Remote Sensing Symposium, IGARSS 95. Quantitative Remote Sensing for Science and Applications; Institute of Electrical and Electronics Engineers (IEEE): Firenze, Italy, 1995; pp. 1979-1981.

19. Guirguis, S.K.; Hassan, H.M.; El-Raey, M.E.; Hussain, M.M.A. Technical Note Multi-temporal change of Lake Brullus, Egypt, from 1983 to 1991. Int. J. Remote Sens. 1996, 17, 2915-2921. [CrossRef]

20. Pietroniro, A.; Leconte, R.; Peters, D.L.; Prowse, T.D. Application of a hydrodynamic model in a freshwater delta using remote sensing. IAHS Publ. 2001, 267, 519-525.

21. Laabs, B.J.; Laufman, D.S. Quaternary highstands in Bear Lake Valley, Utah and Idaho. Geol. Soc. Am. Bull. 2003, 115, 463-478. [CrossRef]

22. Li, L.; Wang, W. The response of lake change to climate fluctuation in north Qinghai-Tibet Plateau in last 30 years. J. Geogr. Sci. 2009, 19, 131-142.

23. Atkinson, C.L.; Julian, J.P.; Vaughn, C.C. Species and function lost: Role of drought in structuring stream communities. Biol. Conserv. 2014, 176, 30-38. [CrossRef]

24. Vaughn, C.C.; Atkinson, C.L.; Julian, J.P. Drought-induced changes in flow regimes lead to long-term losses in mussel-provided ecosystem services. Ecol. Evol. 2015, 5, 1291-1305. [CrossRef] [PubMed]

25. Gaupp, F.; Hall, J.; Dadson, S. The role of storage capacity in coping with Intra and inter-annual water variability in large river basins. Environ. Res. Lett. 2015, 10, 125001. [CrossRef]

26. Fischer, M.; Maag, S. Why Are Cross-Sectoral Forums Important to Actors? Forum Contributions to Cooperation, Learning, and Resource Distribution. Policy Stud. J. 2019, 47, 114-137. [CrossRef]

27. Sun, F.; Zhao, Y.; Gong, P.; Ma, R.; Dai, Y. Monitoring dynamic changes of global land cover types: Fluctuations of major lakes in China every 8 days during 2000-2010. Chin. Sci. Bull. 2014, 59, 171-189. [CrossRef] 
28. Zhu, X.; Ding, J.; Xia, N.; Guo, J.; Zhang, S.; Yang, T.; Wang, J.; Li, X. Temperature vegetation water index: A novel stabilized threshold method for lake surface water mapping. Resour. Sci. 2019, 41, 790-802.

29. Zhou, C.; He, L.; Yang, N. Variations in the Ebinur Lake area caused by human activities and climatic changes. Mar. Geol. Quat. Geol. 2010, 30,121-126. [CrossRef]

30. Sun, A.; Feng, Z.; Ge, X.; Luo, Y.; Li, S.; Yan, F.; Feng, X. Bosten Lake surface area changes analysis using long temporal Landsat image series. J. Image Graph. 2015, 20, 1122-1132.

31. Yue, D. Changes of Large Lake Wetland Area and its Ecological Effect Research in Inner Mongolia. Master's Thesis, Inner Mongolia University, Inner Mongolia, China, 2015.

32. Luo, C.; Xu, C.; Cao, Y.; Tong, L. Monitoring of water surface area in Lake Qinghai from 1974 to 2016. J. Lake Sci. 2017, 29, 1245-1253.

33. Yue, H.; Liu, Y.; Yang, W.T.; Wang, X. Remote sensing analysis on lake area variations of 5 typical lakes in the Northwest of China over the past 40 years. J. Water Resour. Water Eng. 2017, 06, 27-32.

34. Deji, Y.N.; Qiangba, O.; Zeng, L.; Luosang, Q. Lake area variation of Selin Tso in 1975-2016 and its influential factors. Plateau Mt. Meteorol. Res. 2018, 38, 35-41:96.

35. Zeng, X. Discussion on ecological environment protection and green development of Bosten Lake. New West 2016, 17, 45-46.

36. Tang, H. Research on Landsat7 ETM + Data Processing Technology. Ph.D. Thesis, Chinese Academy of Sciences (Institute of Electronics), Beijing, China, 2003.

37. $\mathrm{Xu}, \mathrm{H}$. Comparison of the models for the normalization of Landsat Imagery. Geo. Inf. Sci. 2008, 10, $294-301$.

38. Abulikmu, A.; Spatiotempor, L. Dynamics of the Lakes in the lower reaches of Tarim River. Master's Thesis, Xinjiang Normal University, Xinjiang, China, 2015.

39. Li, X.; Jiang, N.; Zhu, X.; Zhou, J.; Lu, H. Study on lake surface area change of major lakes in the Taihu Basin during the past 30 years. Trans. Oceanol. Limnol. 2006, 4, 17-24.

40. Zhang, L. Research on Reservoir Water Depth Inversion and Water Area Extraction Based on Multi-Band Remote Sensing. Master's Thesis, Inner Mongolia Agricultural University, Inner Mongolia, China, 2018.

41. Yi, G.; Zhang, T. Delayed Response of Lake Area Change to Climate Change in Siling Co Lake, Tibetan Plateau, from 2003 to 2013. Int. J. Environ. Res. Public Health 2015, 12, 13886-13900. [CrossRef]

42. Liang, B.; Qi, S.; Li, Z.; Li, Y.; Chen, J. Dynamic change of lake area over the Tibetan Plateau and Its response to climate change. Mt. Res. 2018, 36, 206-216.

43. Regos, A.; Vidal, M.; Lorenzo, M.; Domínguez, J. Integrating intraseasonal grassland dynamics in cross-scale distribution modeling to support waterbird recovery plans. Conserv. Biol. 2019. [CrossRef]

44. National Bureau of Statistics of China. China Statistical Yearbook; China Statistics Press: Beijing, China, 2014.

45. National Bureau of Statistics of China. China Statistical Yearbook; China Statistics Press: Beijing, China, 2015.

46. National Bureau of Statistics of China. China Statistical Yearbook; China Statistics Press: Beijing, China, 2016.

47. National Bureau of Statistics of China. China Statistical Yearbook; China Statistics Press: Beijing, China, 2017.

48. National Bureau of Statistics of China. China Statistical Yearbook; China Statistics Press: Beijing, China, 2018.

49. Bian, C.; Wang, C.; Li, D. Research on image preprocessing method based on improved median filtering. Electron. World 2018, 18, 22-26.

50. Huang, H. The Research and Application of Mathematical Morphology in Image Edge Detection and Machine Vision. Ph.D. Thesis, Northeastern University, Shenyang, China, 2013.

51. Cui, J.; Guo, A.; Du, R.; Tang, B.; Wang, J.; Zhao, X. Spatial-temporal variations of lakes in Qinghai Province and its responses to climatic change analysis from 1990 to 2015. Resour. Environ. Yangtze Basin 2018, 27, 658-670.

52. He, S. Tidal Channel Information Extraction and Swing Ratio Analysis of Jiuduansha in the Yangtze River Estuary Using Remote Sensing. Master's Thesis, Shanghai Ocean University, Shanghai, China, 2018.

53. Liu, R.; Liu, Y.; Zheng, Z. Quantitative detection of Bosten Lake area using NOAA/AVRR data. J. Appl. Meteorol. Sci. 2006, 17, 100-106.

54. Ayinur, M.; Ümüt, H.; Ayjamal, K.; Song, Z. Remote sensing monitoring of Bosten Lake water sources and its driving factor analysis. Xinjiang Agric. Sci. 2017, 4, 184-192. 
55. Yao, J.; Chen, Y.; Zhao, Y.; Yu, X. Hydroclimatic changes of Lake Bosten in Northwest China during the last decades. Sci. Rep. 2018, 8, 9118. [CrossRef] [PubMed]

56. Taylor, K.E.; Stouffer, R.J.; Meehl, G.A. An overview of CMIP5 and the experiment design. Bull. Am. Meteorol. Soc. Am. 2012, 93, 485-498. [CrossRef]

(C) 2019 by the authors. Licensee MDPI, Basel, Switzerland. This article is an open access article distributed under the terms and conditions of the Creative Commons Attribution (CC BY) license (http://creativecommons.org/licenses/by/4.0/). 